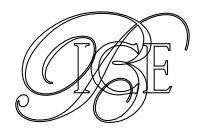

Álvaro Espina*

\section{EL SISTEMA DE PENSIONES ESPAÑOL EN PERSPECTIVA COMPARADA: LA NECESIDAD DE FORTALECER EL TERCER PILAR}

Para determinar la pensión inicial será computable toda la vida laboral, acumulándose anualmente el 1,55 por 100 de la base reguladora. Tras 45 años, la pensión equivaldrá al 70 por 100 de aquella. La tasa de acumulación actual disminuirá paulatinamente y el periodo computable aumentará hasta alcanzar aquellas cifras en 2060, y la edad de jubilación, a los 70 años. Las pensiones perderían poder adquisitivo, disminuyendo paulatinamente esta pérdida hasta desaparecer al término del periodo transitorio. Sin embargo, los nuevos pensionistas podrían optar por acelerar la aplicación de la reforma a su pensión inicial a cambio de mantener constante su poder adquisitivo.

Para fortalecer el tercer pilar se propone subvencionar las aportaciones al fondo de pensiones de los beneficiarios con ingresos por debajo del doble del salario mínimo. Además, en las retiradas se deduciría de la base imponible el 40 por 100 a los jubilados con base reguladora menor o igual al salario mínimo, modulando esta cifra hasta quedar reducida al 5 por 100 para los tramos superiores a cuatro SMI.

Palabras clave: pensión, base reguladora, edad de jubilación, salario mínimo.

Clasificación JEL: H55, J26.

\section{Introducción}

La reforma del sistema español de pensiones contributivas propuesta en Espina (2017c) contiene cuatro medidas:

1. Prorrogar a partir de 2028 el retraso en la edad legal de jubilación establecido en 2011, a razón de un mes por año, llegando a situarla en 70 años en 2063.

\footnotetext{
*Consejero Técnico. Dirección General de Política Económica.
} Versión de noviembre de 2017.
2. Disminuir paulatinamente la ratio de reposición legal, desde el 100 por 100 de la base reguladora actual hasta el 70 por 100 en 2057, reduciéndola 0,5 puntos porcentuales al año entre 2018 y 2037 y un punto porcentual (pp) entre 2038 y 2057. Esta medida sustituiría al factor de sostenibilidad (FS) de la Ley 23/2013.

3. Sustituir el índice de revalorización (IRP) de aquella misma ley por una revalorización con pérdida programada del poder adquisitivo de intensidad decreciente hasta 2066: arrancando con un IRP $\triangleright$ 
equivalente al porcentaje de inflación menos 1,75 pp en 2018, reduciendo este corrector en 0,0306 pp/año hasta el final del periodo proyectado.

4. Aplicar a la pensión de viudedad la regla de reducción del 50 por 100 cuando se compatibiliza con una pensión contributiva propia o un salario pleno, en paralelo con lo que sucede actualmente con la pensión de jubilación'1.

Además, la nueva reforma consolidaría la financiación de los complementos a mínimos de las pensiones contributivas por los Presupuestos Generales del Estado, dado su carácter propiamente no contributivo -algo que hasta el momento viene regulándose por la ley de presupuestos de cada año-, de modo que dentro del sistema español de pensiones descrito en Espina (2017b) todo el primer pilar se financiaría con impuestos y el segundo pilar con cotizaciones. Bien es verdad que las pensiones públicas del sistema de clases pasivas (a extinguir) se financian con los presupuestos, pero a través de una partida que para la Contabilidad Nacional tiene la consideración de «cotizaciones ficticias». Para que la reforma sea coherente la Administración debería garantizar que la evolución relativa de las pensiones de quienes permanecen en el sistema de clases pasivas, hasta su extinción definitiva, se adapta a la de las pensiones del Régimen General a través de la ley anual.

La propuesta pretende distribuir equitativamente entre las diferentes generaciones de pensionistas la reducción de expectativas en el poder adquisitivo de la ratio real de reposición pensión/salario necesaria para hacer frente a

1 España es uno de los cuatro países de la UE en que la pensión de viudedad supera en más del 50 por 100 la pensión que corresponde a las personas con bajos ingresos (Comisión Europea, 2015b, V. 1, fig. 12). los choques demográficos ineluctables, que el trabajo mencionado estima en un 25 por 100 en media para todo el periodo, con respecto a una situación sin reforma ${ }^{2}$. Para compensar tal reducción se recomendaba una política de fortalecimiento del tercer pilar del sistema «fomentando la acumulación de fondos de pensión privados compensatorios con fuerte apoyo fiscal durante el periodo de transición», de acuerdo con las mejores prácticas llevadas a cabo por los sistemas de pensiones de nuestro entorno internacional más afín.

Este trabajo empieza contrastando las proyecciones en que se basaba aquella propuesta de reforma con los escenarios planteados por el FMI (2017) y con las recomendaciones contenidas en su informe. El resto del estudio examina las principales características de las reformas llevadas a cabo en la OCDE en busca de las mejores prácticas para acometer las reformas propuestas -o sus variantes-, y para el tercer pilar del sistema.

\section{Un contraste de los resultados previstos en la propuesta de reforma del sistema español de pensiones con el último dictamen del FMI}

Nuestro trabajo de Espina (2017c) emplea denominaciones y conceptos que se separan de lo más usual con objeto de hacer énfasis en la funcionalidad de cada concepto e incorporar alguna novedad. Por ejemplo, en lugar de emplear la ratio de dependencia se usa su inversa, la ratio de capacidad demográfica (RCD), que apunta directamente a la capacidad de $D$

2 En el trabajo de Díaz y Díaz (2017), la pérdida derivada de las reformas de 2011 y 2013 se eleva al 30 por 100, respecto a la situación sin reforma, pero gravita desproporcionadamente sobre los futuros jubilados. 
financiación del sistema, pero se mide de forma ligeramente diferente; en lugar de la ratio de elegibilidad se emplea la de cobertura (Rcob), puesto que mide precisamente la proporción de personas mayores cubiertas $-\mathrm{y}$ también aporta novedades de medición-, y en lugar de la ratio de empleo se usa la de cotización (RCot), más próxima a la tasa de actividad, que incluye igualmente a los desempleados protegidos, ya que también cotizan (algo relevante para la cuentas de la Seguridad Social).

Además, se dan algunos rodeos para evitar que la proyección dependa de una desmesurada acumulación de supuestos. Por ejemplo, para obviar las proyecciones de salarios se toma como unidad de medida el salario medio anual del año en curso, operando exclusivamente con sus ratios (como la ratio de reposición pensión salario, $\sigma$, o la de cotización, $\tau$ ), relacionándolas con otras ratios o múltiplos de esa magnitud en el mismo año, lo que elimina igualmente la necesidad de modelizar el crecimiento de la productividad y el PIB (pero impide conocer la cuantía absoluta del poder adquisitivo de las pensiones). Como el propósito de este nuevo trabajo consiste en el estudio comparado de nuestro sistema y su reforma, es preciso reconducir aquellos conceptos y escenarios, haciéndolos compatibles con las bases de datos e informes internacionales disponibles, siempre que tal cosa sea posible sin erosionar su significado.

A título de ilustración, ensayaremos la equiparación de nuestra proyección con la que resulta implícita en el informe del FMI sobre España para «las consultas del artículo IV» del año 2017, comenzando por especificar las diferencias en la forma de aproximar el problema en uno y otro caso a partir de la identidad empleada por el informe del fondo para descomponer la ratio gasto en pensiones/PIB, como se ve en la expresión [1].

Como acaba de comentarse, nuestra proyección evita cuidadosamente apoyarse sobre escenarios de crecimiento del PIB y de la productividad, de modo que para hacer una primera comparación debemos prescindir del $\mathrm{PIB}$, transponiendo el último término de esta expresión al primer miembro. Al mismo tiempo, en nuestra proyección final se adoptaba la convención de medir las ratios de dependencia y de elegibilidad (con otra denominación) no con respecto a una divisoria fija para la edad de jubilación, sino sustituyéndola por la edad de jubilación establecida para cada año por la reforma de 2011, prorrogándola hasta alcanzar los setenta años en 2063, algo que conviene mantener en este ejercicio, en aras del rigor metodológico. Por lo que se refiere a la ratio de empleo (REmp), es muy razonable diferenciarla de la ratio de cotizantes, puesto que, aunque los desempleados también coticen, lo hacen con cargo a unos conceptos de cotización que no se corresponden con los de cotización para las pensiones. Con estas salvedades, denominando GP al gasto en pensiones y RA a la remuneración de asalariados, podemos reconvertir la expresión [1], usada por el FMI, en la expresión [2].

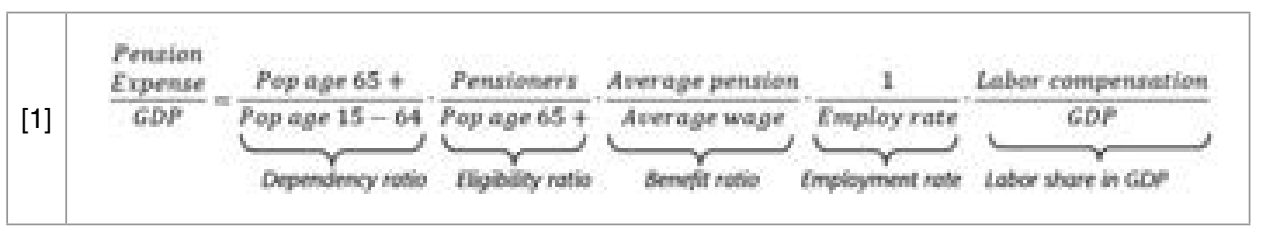

[2] $\mathrm{GP} / \mathrm{RA}=(1 / \mathrm{RCD}) \cdot \mathrm{Rcob} \cdot \sigma \cdot(1 / \mathrm{REmp})$ 


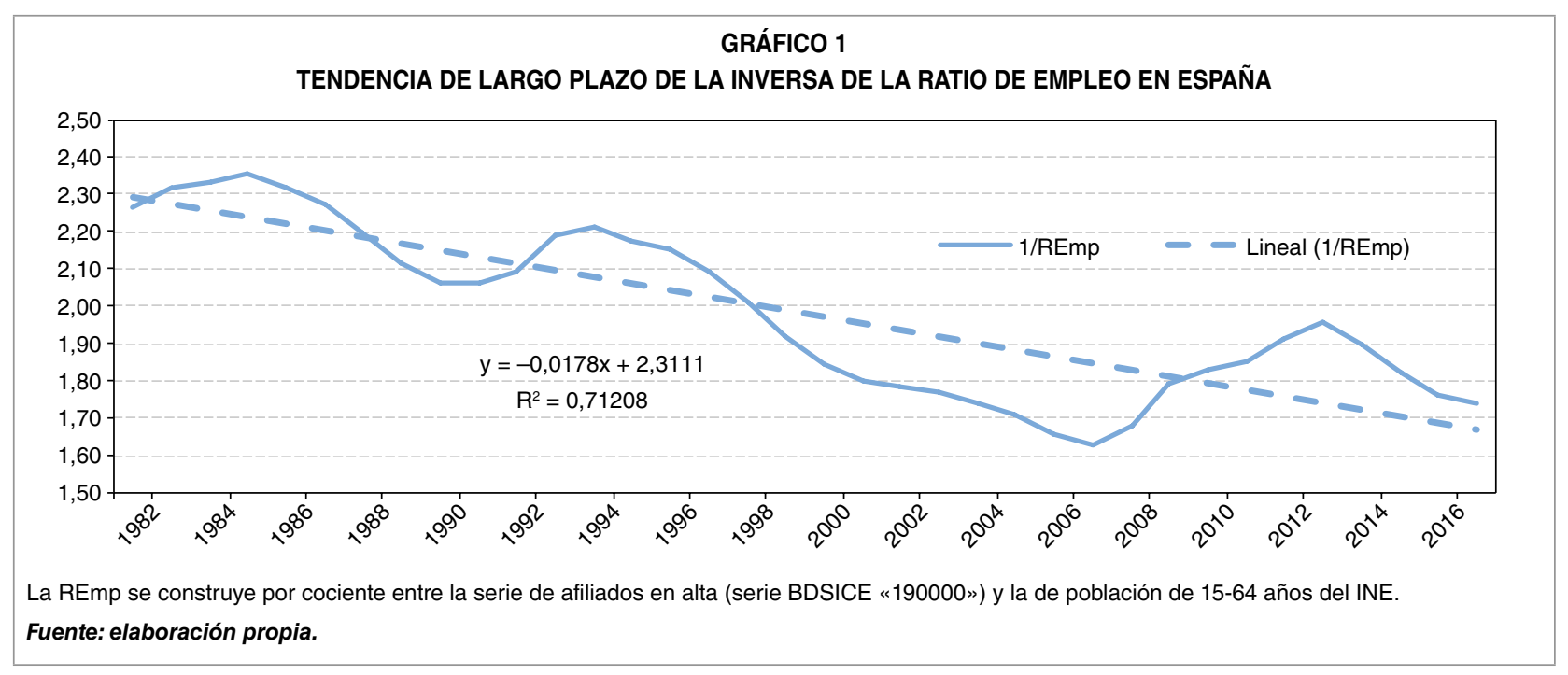

Se aproxima mucho a la nuestra y sirve para observar directamente la marcha de la ratio GP/RA, o «ratio gasto/remuneración». Para que el sistema se mantenga en equilibrio presupuestario esta ratio debe igualarse a la «ratio ingreso/ remuneración", equivalente a escala agregada al tipo de cotización para la pensión ${ }^{3}, \tau$. Para contrastar los resultados obtenidos con los enunciados por el informe del FMI, además de realizar una proyección específica para la inversa de la tasa de empleo solo hay que cambiar dos cosas: la tasa máxima alcanzada por esta ratio en el horizonte de la proyección y su equivalente en la ratio de cobertura de las pensiones, ya que, como se recordará, una y otra coinciden, con un cierto desfase temporal, puesto que el «derecho a la elegibilidad» para la pensión contributiva se adquiere con el empleo, cotizando durante el periodo de vida activa. En las estimaciones del FMI esta cifra alcanza un máximo del 79 por

3 Denominando CP a la masa de cotizaciones sociales para la pensión $\tau=\mathrm{CP} / \mathrm{RA}$ y, bajo la restricción de mantener $\tau$ constante, la condición de equilibrio es GP/RA = CP/RA. Téngase en cuenta, sin embargo, que la RA de Contabilidad Nacional incluye impuestos y cotizaciones de empresarios y trabajadores, mientras que nuestra proyección parte de la magnitud "coste salarial», que solo incluye los de los trabajadores. Bien es verdad que bajo el supuesto de tipos fijos, la pendiente es común a ambas series.
100, mientras que en nuestra proyección la Rcot llegaba al 82 por 100 en 2049, estabilizándose y equiparándose a partir de entonces con la ratio de cobertura o elegibilidad. Por su parte, la extrapolación de la inversa de la ratio de empleo se hace con la tendencia estimada en el Gráfico 1, iniciando el cómputo $(t=1)$ en 1982.

Asumidas estas salvedades, los resultados del ejercicio aparecen en el Cuadro 1 y en el Gráfico 2. En el cuadro puede observarse que las ratios GP/RA para cualquier ratio de reposición aumentan un 53 por 100 a lo largo de los sesenta años, y un 28 por 100 desde 2015 (30 por 100, entre 2016 y 2066) en los términos de la identidad del FMI (aunque aplicando la reforma de 2011 y extrapolándola). Como la reforma propuesta va reduciendo el valor efectivo real de $\sigma$ a lo largo del tiempo, la simulación de los efectos de la misma se observa desplazándose hacia la columna derecha cada quince años, comprobándose que de esa forma la ratio de gasto se mantiene prácticamente constante, con ligeras fluctuaciones (sobre todo en el decenio de los años veinte), a lo largo de todo el periodo, situándose en 2065 por debajo de su nivel en 2015 , como indican las cifras $D$ 
EL SISTEMA DE PENSIONES ESPAÑOL EN PERSPECTIVA COMPARADA...

CUADRO 1

LA REFORMA DEL SISTEMA ESPAÑOL DE PENSIONES MEDIDA CON LA IDENTIDAD DEL FMI: GP/RA $=(1 / R C D) \cdot R C O B \cdot(1 / R E M P) \cdot \sigma$, PARA CUATRO VALORES DE $\sigma$

\begin{tabular}{|c|c|c|c|c|c|c|c|}
\hline \multirow{2}{*}{ Años } & \multirow{2}{*}{ 1/RCD } & \multirow{2}{*}{ Rcob } & \multirow{2}{*}{ 1/REmp } & \multicolumn{4}{|c|}{ GP/RA: Gasto pensiones/Rem. de asalariados } \\
\hline & & & & $(\sigma=65 \%)$ & $(\sigma=60 \%)$ & $(\sigma=55 \%)$ & $(\sigma=50 \%)$ \\
\hline 2005 & $24,0 \%$ & $76,4 \%$ & 1,71 & $20,4 \%$ & $18,9 \%$ & $17,3 \%$ & $15,7 \%$ \\
\hline 2010 & $24,7 \%$ & $75,5 \%$ & 1,83 & $22,1 \%$ & $20,4 \%$ & $18,7 \%$ & $17,0 \%$ \\
\hline 2015 & $27,1 \%$ & $76,0 \%$ & 1,82 & $\underline{24,4 \%}$ & $22,6 \%$ & $20,7 \%$ & $18,8 \%$ \\
\hline 2020 & $28,3 \%$ & $76,0 \%$ & 1,60 & $22,3 \%$ & $20,6 \%$ & $18,9 \%$ & $17,2 \%$ \\
\hline 2025 & $29,4 \%$ & $76,8 \%$ & 1,51 & $22,2 \%$ & $20,5 \%$ & $18,8 \%$ & $17,1 \%$ \\
\hline 2030 & $32,4 \%$ & $77,6 \%$ & 1,42 & $23,2 \%$ & $\underline{21,4 \%}$ & $19,6 \%$ & $17,8 \%$ \\
\hline 2035 & $36,8 \%$ & $78,4 \%$ & 1,33 & $25,0 \%$ & $23,1 \%$ & $21,1 \%$ & $19,2 \%$ \\
\hline 2040 & $41,7 \%$ & $79,0 \%$ & 1,27 & $27,1 \%$ & $25,0 \%$ & $22,9 \%$ & $20,9 \%$ \\
\hline 2045 & $47,2 \%$ & $79,0 \%$ & 1,27 & $30,7 \%$ & $28,3 \%$ & $\underline{25,9 \%}$ & $23,6 \%$ \\
\hline 2050 & $51,5 \%$ & $79,0 \%$ & 1,27 & $33,5 \%$ & $30,9 \%$ & $28,3 \%$ & $25,8 \%$ \\
\hline 2055 & $52,2 \%$ & $79,0 \%$ & 1,27 & $33,9 \%$ & $31,3 \%$ & $28,7 \%$ & $26,1 \%$ \\
\hline 2060 & $50,4 \%$ & $79,0 \%$ & 1,27 & $32,8 \%$ & $30,2 \%$ & $27,7 \%$ & $\underline{25,2 \%}$ \\
\hline 2065 & $48,2 \%$ & $79,0 \%$ & 1,27 & $31,3 \%$ & $28,9 \%$ & $26,5 \%$ & $\underline{24,1 \%}$ \\
\hline \multicolumn{8}{|c|}{$\begin{array}{l}\text { La construcción de las variables RCD y Rcob se hizo en Espina (2017c). La extrapolación de la serie 1/REmp se realiza con los coeficientes de tenden } \\
\text { cia que aparecen en el Gráfico 1. Las últimas cuatro columnas y las series GP/RA se calculan con la identidad [2] para los correspondientes } \sigma \text {. }\end{array}$} \\
\hline
\end{tabular}

coloreadas y la del año final. Además, la ratio alcanzada con la reforma en 2066 (47 por 100), aplicada a las cifras del Cuadro 1, situaría la ratio gasto/remuneración de 2065 en 22,6 por 100, por debajo del nivel de 2011.
Su representación gráfica permite observar que hasta 2038 el aumento de la tasa de dependencia se ve compensado con creces por el descenso de la inversa de la ratio de empleo, mientras que la de cobertura (o de elegibilidad) $D$

GRÁFICO 2

LA PROPUESTA DE REFORMA DE LAS PENSIONES: EVOLUCIÓN DE LAS PRINCIPALES VARIABLES EN LOS TÉRMINOS UTILIZADOS EN EL INFORME DEL FMI

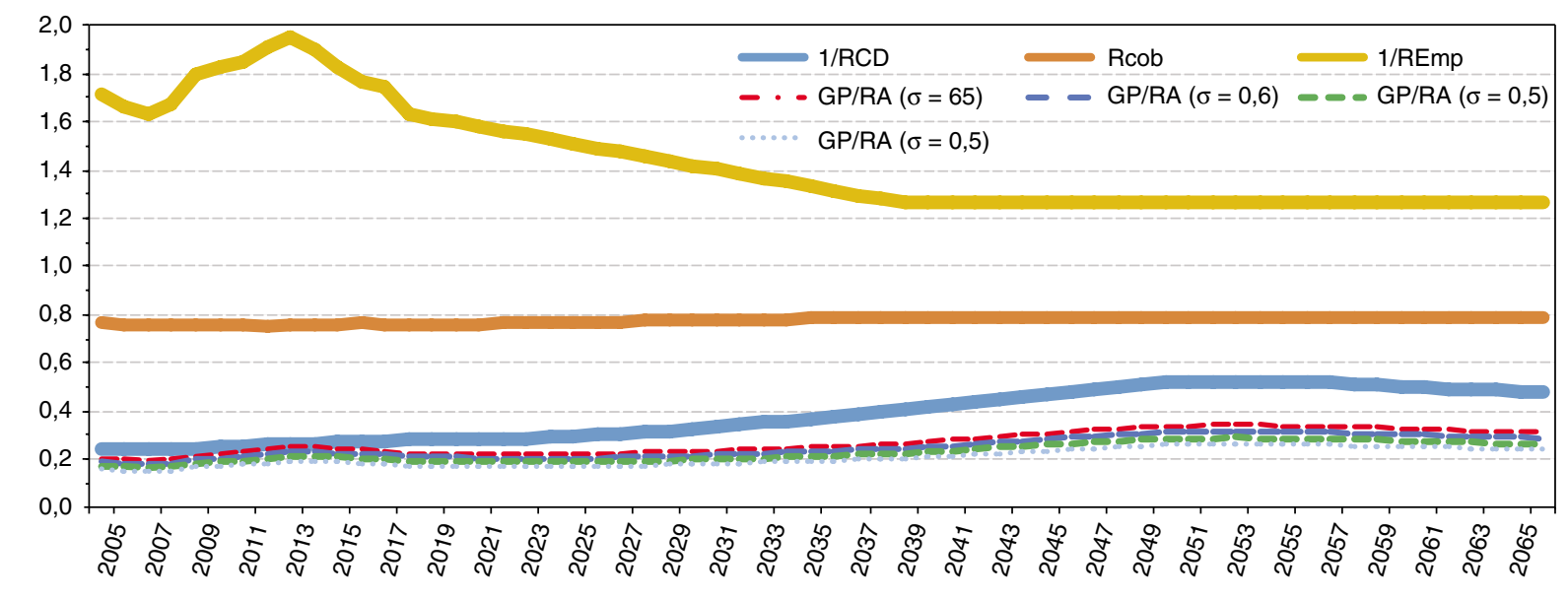

La REmp se construye por cociente entre la serie de afiliados en alta (serie BDSICE «190000») y la de población de 15-64 años del INE.

Fuente: elaboración propia. 


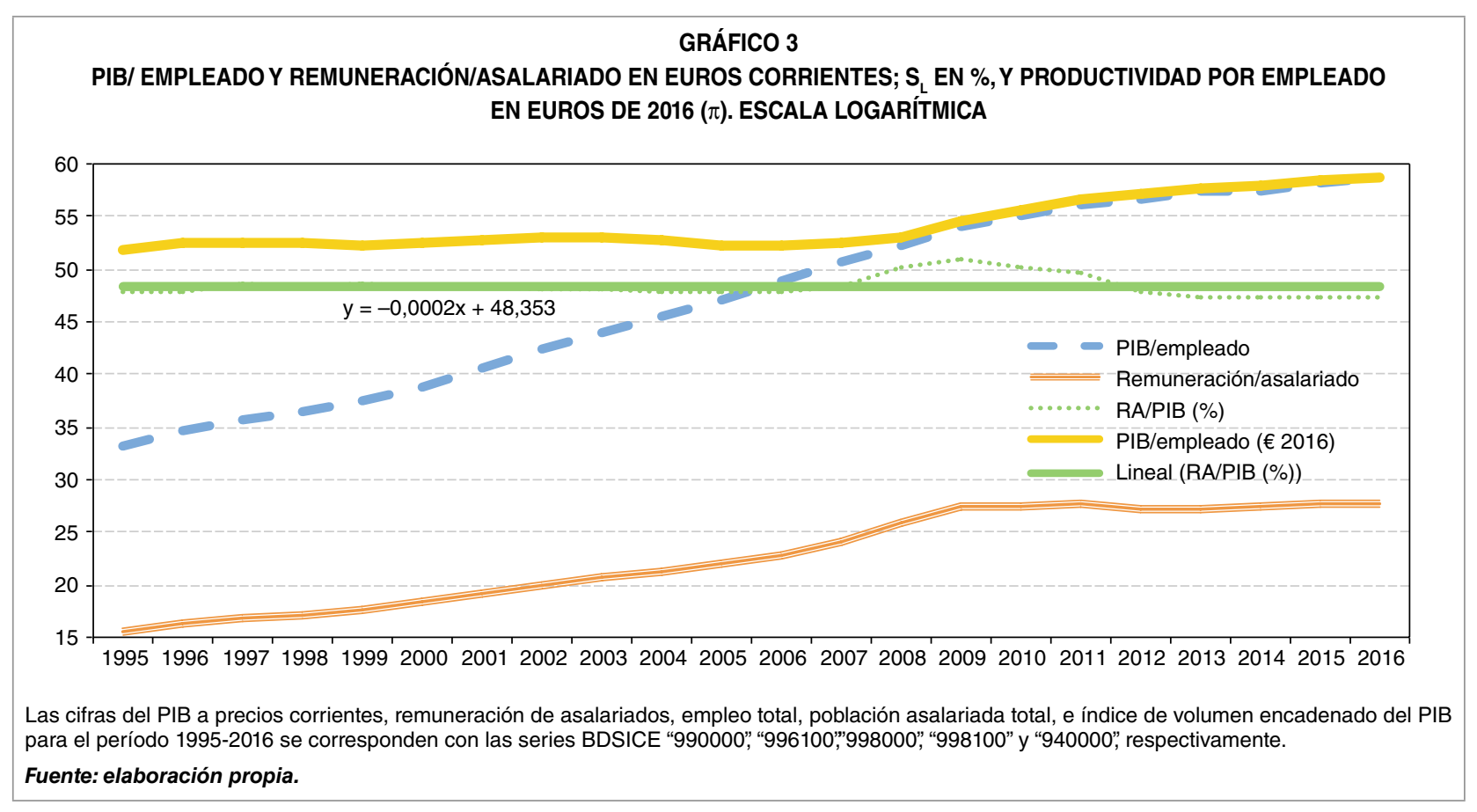

apenas deja sentir su influencia (de hecho, en el escenario del FMI se mantiene constante). En cambio, desde esa fecha el factor demográfico no se ve compensado, presionando al alza sobre la ratio de gasto, que solo comienza a disminuir a partir de 2050 , al cesar aquella presión. Las cuatro líneas discontinuas de trazo fino en el Gráfico 2 representan la evolución de la ratio GP/RA y evidencian que, grosso modo, al desplazarnos paulatinamente entre los cuatro valores de $\sigma$, con $\tau$ constante el equilibrio presupuestario del sistema se mantiene tras la reforma.

Aunque en nuestra propuesta no se trasladaban los resultados de la proyección a magnitudes relativas de gasto en pensiones respecto al PIB, o «ratio de gasto en pensiones» $\left(g_{p}\right)$, ni se tomaba como punto de referencia la ratio RA/PIB —o sea, la participación de los salarios en el PIB, (o share: $\mathrm{s}_{\mathrm{L}}$ )-, la proyección de la «ratio de ingresos del sistema», como hace el informe del FMI, puede realizarse de forma sencilla suponiendo distintos escenarios de crecimiento tendencial de la productividad $(\pi)^{4}$, sin necesidad de apelar a modelos macroeconómicos complejos, cuya fragilidad se ha puesto de manifiesto durante la Gran Recesión ${ }^{5}$.

En el Gráfico 3 se ha dibujado la evolución de las principales ratios del triángulo de magnitudes: remuneración de asalariados, PIB y empleo (diferenciando entre empleo total y empleo asalariado) desde 1995. Puede observarse que durante esos 22 años la remuneración por asalariado $(w)$ y el PIB por empleado medidos a precios corrientes han evolucionado $D$

\footnotetext{
4 Haciendo abstracción de las transferencias desde los presupuestos del Estado, los ingresos del sistema equivalen a $\mathrm{CP}$ y su ratio responde a la identidad $\mathrm{CP} / \mathrm{PIB}=\mathrm{CP} / \mathrm{RA} \cdot \mathrm{RA} / \mathrm{PIB}=\tau \cdot \mathrm{s}$. Por su parte, podemos expresar la ratio de gasto en pensiones $\left(g_{P}\right)$ de la misma forma: $g_{P}=G P /$ $\mathrm{PIB}=\mathrm{S}_{\mathrm{L}} \cdot \mathrm{GP} / \mathrm{RA}$. La condición de equilibrio del sistema contributivo exige que $\mathrm{GP}=\mathrm{CP}$ (e igualmente que GP/RA = CP/RA, o que GP/PIB = CP/ PIB); esto es, que $g_{P}=s_{L} \cdot G P / R A=\tau \cdot s_{L}$, de modo que debe cumplirse también que GP/RA $=\tau=\mathrm{CP} / \mathrm{RA}$ y, finalmente, que $s_{L}=g_{P} / \tau$.

5 El fracaso de los modelos DSGE para entender la dinámica subyacente a las economías reales de nuestro tiempo los convierte en una herramienta inútil para la predicción. Las alternativas distan mucho de encontrarse disponibles en la práctica, por mucho que el esfuerzo de Stiglitz (2017a) resulte clarificador. Pero habrá que trabajar mucho en los próximos años para hacer aplicable el modelo de su apéndice. Por otra parte, para Aghion et al. (2017), la irrupción de la inteligencia artificial (Al) conducirá probablemente a una etapa de crecimiento lento, debido a la restricción derivada del «mal de coste», o «efecto Beaumol».
} 
en paralelo hasta 2009 (con tasas de crecimiento anual de 3,2 por 100 y 3,3 por 100, respectivamente), mientras que durante los últimos siete años la primera ratio prácticamente se estancó ( $w$ creció al 0,13 por 100) al tiempo que la ratio PIB/EMP moderaba drásticamente su crecimiento hasta una tasa de 1,2 por 100.

En el gráfico puede observarse también que la productividad por empleado $(\pi=\mathrm{PIB} / \mathrm{EMP}$, en euros 2016) se mantuvo prácticamente constante hasta 2007 —al igual que ocurrió en Italia-, y en los últimos nueve años creció a una tasa anual de 1,2 por 100, de modo que la tasa media del periodo completo se situó en 0,57 por 100. En cambio, aunque con fluctuaciones cíclicas la share $\left(\mathrm{s}_{\mathrm{L}}=\mathrm{RA} / \mathrm{PIB}\right)$ se mantuvo prácticamente constante, ya que su línea de tendencia es casi perfectamente plana, lo que indica que el salario medio creció casi exactamente igual que la productividad, dado que la población asalariada (ASA) evolucionó en paralelo con el empleo (EMP) ${ }^{6}$.

El informe del FMI mantiene $s_{L}$ constante a lo largo de todo el periodo proyectado, situándola en el nivel de 2016 (47,2 por 100), lo que implica suponer también que los salarios crecerán igual que la productividad. En nuestro caso, al no observar tendencia alguna de largo plazo y encontrarse los salarios claramente deprimidos en la última etapa, de tomar esta ratio como variable exógena consideraríamos más realista mantener la $s_{L}$ media de todo el periodo $(48,35 \text { por } 100)^{7}$, e igualmente constante, pero no hay necesidad de hacerlo, puesto que en nuestra proyección esa ratio queda determinada de forma endógena ${ }^{8}$. Por lo que se refiere a

\footnotetext{
6 La expresión $s_{L}=$ RA/PIB equivale a $s_{L}=(w \cdot A S A) /(\pi \cdot E M P), y$ como la correlación entre las series $A S A$ y $E M P$ fue $R=0,998$, la de $w$ y $\pi$ fue también prácticamente unitaria.

7 Ya que la caída de $s_{L}$ solo es consistente con un descenso de la productividad (Grossman et al. 2017).

8 Hernández de Cos, Jimeno y Ramos (2017) la mantienen también constante de forma exógena en la media de 1980-2015 (48 por 100). En su
}

la productividad, el escenario más realista se sitúa algo por debajo del planteado por los investigadores del $\mathrm{BdE}$ (1,5 por 100$)$, que casi triplica la registrada los últimos veinte años ${ }^{9}$. Por mucho que las reformas estructurales puedan aumentarla, parece prudente operar con un escenario base de aumento del 1 por 100 anual (aunque explorando la horquilla entre 0,5 por 100 y 1,5 por 100), ya que las causas del estancamiento parecen encontrarse, como en Italia, en la incapacidad para explotar las tecnologías de la información por el carácter escasamente meritocrático de la selección de los cuadros y directivos, algo muy difícil de desarraigar (Pellegrino-Zingales, 2017).

Si este fuera el caso y los salarios absorbieran todo ese crecimiento, el salario real medio pasaría de un índice 100 en 2016 a otro 164,5 en 2066 y la pensión media pasaría del 65 por 100 del salario real medio de 2016 al 77,3 por 100 del mismo de ese mismo año (47 por 100 del índice alcanzado por el salario real), creciendo un 18,9 por 100 . El gasto en pensiones crecería un 77 por 100 (resultado de acumular el crecimiento de la pensión media y el del número de pensiones, estimado este último en el 48,8 por 100$)$. Como en nuestra proyección la población empleada se mantiene prácticamente constante (en torno a 20 millones, si se incluyen los desempleados cotizantes), el crecimiento del PIB real al término del periodo proyectado sería idéntico al del salario real y al de la productividad (64,5 por 100), de modo que el crecimiento de la ratio de gasto en pensiones sería el resultado del cociente entre esos dos índices $\left(\Delta \mathrm{g}_{\mathrm{P}}=1,77 / 1,645=1,076\right)$, o sea, un 7,6 por 100 , que se encuentra dentro $D$

\footnotetext{
simulación, la productividad/hora crece a una tasa del 1,5 por 100 y el PIB, a otra del 1,8 por 100 (aunque 2,3 por 100 hasta 2010).

9 Ese es el supuesto de OECD (2016a, p. 47) para todo el área, aunque OECD (2015) lo sitúa en 1,25 por 100.
} 
de márgenes de crecimiento comparativamente asumibles, que podría financiarse con imposición sobre las rentas del capital, que a estos efectos tiene carácter Pareto-eficiente y puede mejorar la productividad (Stiglitz, 2017b).

Aplicado ese crecimiento a la cifra total de $g_{p}$ en 2016 del sistema contributivo, significaría pasar del 10,66 por 100 actual al 11,47 por 100 en 2066. Por su parte, la ratio $s_{L}$ se mantendría efectivamente en el nivel de 2016 (47,3 por 100). Finalmente, el poder adquisitivo de la pensión media del sistema crecería a una tasa anual del 0,35 por 100 . Con políticas que aumentasen el crecimiento de la productividad hasta el 1,5 por 100, el salario real crecería un 110 por 100 y el poder adquisitivo de la pensión media, un 52 por 100 (a una tasa anual del 0,844 por 100 ); en cambio, con un crecimiento del 0,5 por 100 el salario real crecería un 58 por 100, pero el poder adquisitivo de la pensión media caería un 7,2 por 100 (a una tasa anual de $-0,15$ por 100). En ambos casos, la ratio de gasto en pensiones contributivas se mantendría en 11,47 por 100.

Todas estas estimaciones se realizan a partir de la proyección de los parámetros de las pensiones del sistema general extrapoladas al conjunto del sistema contributivo. En el Cuadro 2 se realiza además la extrapolación al conjunto del sistema de pensiones, agregando las pensiones no contributivas y las de clases pasivas, con lo que el $g_{p}$ pasaría del 12,1 por 100 del PIB al 13,02 por 100 en esos cincuenta años. Como ya se dijo, ello implica que la ley anual de presupuestos aplicará igualmente las pautas de la reforma a la evolución de las pensiones de clases pasivas a extinguir, y para completar el proceso de ajuste el primer pilar debería evolucionar pari pasu con el segundo. Por lo que se refiere a los complementos a mínimos, es previsible que, incluso manteniendo estos en una banda paralela a la evolución de las pensiones medias, el gasto real aumente al hacerlo la proporción de quienes no lo alcanzan en el régimen contributivo ${ }^{10}$, pero probablemente eso se verá compensado por una reducción de las pensiones máximas, guardando un cierto paralelismo con las ratios de reposición de las pensiones medias, aunque tomando en consideración que sus ratios ya son regresivas, con vistas a no dañar el incentivo contributivo a la cotización de los salarios superiores.

En cambio, resulta escasamente probable y no deseable aplicar medidas de pérdida del poder adquisitivo a las pensiones no $\square$

10 Debe tenerse en cuenta que, después de Luxemburgo, la pensión mínima española es la mayor de la Unión Europea como proporción del ingreso medio (33,9 por 100: OECD, 2015; fig. 2.4, t. 5.3) y que los años requeridos para alcanzarlo (15) solo superan a los de Francia (10), que exige prueba de medios (fig. 2.2).

CUADRO 2

SISTEMA ESPAÑOL DE PENSIONES. GASTO EN 2016 Y ESTIMACIÓN 2066

\begin{tabular}{|c|c|c|c|c|}
\hline Pensiones & $\begin{array}{c}\text { Gasto } 2016 \\
\text { (En miles de euros) }\end{array}$ & $\%$ sobre total & $\%$ sobre PIB $\left(g_{P}\right)$ & Estim. g 2066 (\%) \\
\hline Contributivas Seg. Social & 119.021 .801 & 88,07 & 10,66 & 11,47 \\
\hline No contrib. Seg. Soc. y PAS & 2.350 .294 & 1,74 & 0,21 & $0,23-0,33$ \\
\hline Clases pasivas & 13.775 .691 & 10,19 & 1,23 & 1,33 \\
\hline Total & 135.147 .786 & - & - & - \\
\hline Total en \% RA & 25,70 & - & - & - \\
\hline Total en \% PIB $\left(g_{p}\right)$ & 12,10 & - & - & $13,02-13,12$ \\
\hline
\end{tabular}


contributivas y asistenciales, por lo que puede pensarse que a lo largo del periodo proyectado su peso relativo podría aumentar ligeramente ${ }^{11}$, con lo que el $g_{p}$ alcanzaría el 13,12 por 100 del PIB en 2066, dos puntos más que la media estimada para el conjunto de la OCDE en 2060 (que coincide prácticamente con la de la UE-28) y casi un punto porcentual por encima de la de la eurozona ${ }^{12}$.

\section{La perspectiva comparada: situación actual e impacto de las reformas}

En el Cuadro 3 se han calculado las ratios medias de reposición para España, Francia, Alemania e Italia, además de las de EEUU, la OCDE-34 y la UE-28. Estas ratios se calculan, a su vez, como media de seis datos, correspondientes a aplicar los parámetros de cada sistema a tres situaciones de ingresos, equivalentes a la mitad, una vez y 1,5 veces el ingreso medio a lo largo de toda la vida laboral (con edad de entrada a los veinte años y la edad de salida legal en cada país en 2015), tanto para hombres como para mujeres. La ratio bruta es el cociente entre pensión bruta e ingresos brutos, incluidos impuestos y cotizaciones ligadas al trabajo (tanto del trabajador como de la empresa); la ratio neta excluye todos estos conceptos. Se distingue entre pensión obligatoria (sea esta pública o privada, incluyendo en este caso los planes ocupacionales centralizados que cubren a más del 90 por 100 de la población) y pensión total, que incluye el ahorro

11 Ya que mantener su peso exigiría practicar una de las políticas de

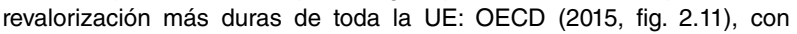
pérdida anual constante del 1,5 por 100 del poder adquisitivo respecto a los salarios para los mayores de 70 años.

12 En la estimación de la CE (2015a, t. II.1.11), la ratio para la eurozona es 12,3 por 100 . privado no obligatorio para pensión. Los supuestos de base son los mismos para los treinta países estudiados: tasa de crecimiento anual de los ingresos reales de 1,25 por 100, inflación de 2 por 100 y tipo de descuento real para los cálculos actuariales de 2 por 100. En cambio, la tasa anual de retorno para los planes de pensiones DC (aportación definida) es del 3 por $100^{13}$-un punto porcentual superior al tipo de descuento- y su factor de conversión, el 85 por 100 (descontando las comisiones: tipo efectivo de 2,55 por 100). Se ha calculado también la riqueza en pensiones derivada de aplicar el modelo OCDE para capitalizar los derechos adquiridos para la pensión obligatoria neta.

Debe observarse que todos estos cálculos difieren en su metodología de los realizados en Espina (2017b y 2017c), ya que en este caso los cálculos de ratios de reposición se realizaron con las cifras agregadas efectivas de pensión media y salario medio, proyectando las tendencias tanto del conjunto del sistema como de su Régimen General, y con las pensiones medias correspondientes a las nuevas altas en relación con las ratios de reposición teórica establecidas por la regulación para estas últimas. A su vez, la riqueza en pensiones se estimó directamente como proporción del salario medio anual de cada año, evitando simular escenarios de inflación y tipos o agregados nominales.

Aunque no refleje la realidad efectiva de cada país, la metodología OCDE permite establecer, sin embargo, comparaciones sobre situaciones comunes para el conjunto de los países del área, a la vista de sus parámetros, y, dada la divergencia inicial que se observa $\triangle$

13 Ninguno de estos parámetros se separa de los de España en más de una décima (Ibíd., fig. 4.2). 
en el Cuadro 3, evaluar el significado de la reforma realizada en España (coincidente en esto con nuestra propuesta) en términos de aproximación a la situación vigente en el conjunto de la comunidad internacional más desarrollada.

En la parte superior del Cuadro 3 se calculan las cifras absolutas y en la inferior, el múltiplo a que la cifra española equivale respecto de las otras, para los seis casos de nuestra comparación. Cabe señalar, en primer lugar, la anomalía de los cálculos de la OCDE para la riqueza en pensiones del sistema obligatorio de Alemania, que duplica con creces la de EEUU, teniendo ratios de reposición muy similares, y supera en un tercio a Francia, cuya ratio es una tercera parte superior. Hecha esa salvedad -que se debe sin duda al cómputo del tercer pilar, aun siendo «voluntario», vía negociación colectiva, con lo que Alemania y
Francia quedan casi equiparadas en pensión total-, puede decirse que en 2014 la ratio neta de reposición del sistema obligatorio español de pensiones se separa entre 23 y 37 por 100 de la media del conjunto de la Unión Europea y de la OCDE, respectivamente, y que estas cifras relativas se amplían hasta 35-46 por 100 si se computa la riqueza neta en pensiones de tal sistema. El rango de esas desviaciones enmarca precisamente la intensidad de la corrección estimada para los efectos de la reforma propuesta (Espina, 2017c), que puede ser considerada por eso mismo como una forma de «realineamiento con la media», por mucho que no sea esa la finalidad última de la reforma, sino la de alcanzar la sostenibilidad del sistema a largo plazo.

La última columna del Cuadro 3 mide en puntos porcentuales la variación esperada $\square$

CUADRO 3

RATIOS DE REPOSICIÓNY RIQUEZA DE LOS SISTEMAS DE PENSIONES

(EN \% DE LOS INGRESOS INDIVIDUALES Y COMO MÚLTIPLO DEL INGRESO/AÑO: 2014) Y GP/PIB 2015-2060

\begin{tabular}{|c|c|c|c|c|c|c|c|}
\hline & \multicolumn{2}{|c|}{ Pensión obligatoria } & \multirow{2}{*}{$\begin{array}{c}\text { Riqueza } \\
\text { Pensión neta }\end{array}$} & \multicolumn{2}{|c|}{ Pensión total (+ vol.) } & \multirow{2}{*}{$\begin{array}{l}\text { GP/PIB } \\
\text { *en\% }\end{array}$} & \multirow{2}{*}{$\begin{array}{c}\text { GP/PIB } \\
\text { variación } \\
\text { (pp) }\end{array}$} \\
\hline & $\begin{array}{l}\text { Ratio de } \\
\text { reposición }\end{array}$ & $\begin{array}{l}\text { Ratio de } \\
\text { reposición }\end{array}$ & & $\begin{array}{l}\text { Ratio de } \\
\text { reposición }\end{array}$ & $\begin{array}{l}\text { Ratio de } \\
\text { reposición }\end{array}$ & & \\
\hline & Bruta \% & Neta \% & (w/año) & Bruta \% & Neta \% & 2010-2015 & 2015-2060 \\
\hline España & 82,1 & 89,3 & 13,6 & 82,1 & 89,3 & 11,8 & $-0,8$ \\
\hline Francia & 53,5 & 65,5 & 9,7 & 53,5 & 65,5 & 14,9 & $-2,8$ \\
\hline Alemania & 37,5 & 50,8 & 13,1 & 50,0 & 64,7 & 10,0 & 2,7 \\
\hline Italia & 69,5 & 81,2 & 10,6 & 69,5 & 81,2 & 15,7 & $-1,9$ \\
\hline EEUU & 36,2 & 46,0 & 6,0 & 68,8 & 83,5 & 4,9 & $* * 1,2$ \\
\hline OCDE 34 & 55,1 & 65,3 & 9,3 & 59,7 & 70,5 & 9,0 & 2,3 \\
\hline UE-28 & 61,1 & 72,7 & 10,1 & 64,2 & 75,0 & 11,3 & $-0,2$ \\
\hline \multicolumn{8}{|c|}{ Ratio España/otros países } \\
\hline Francia & 1,54 & 1,36 & 1,39 & 1,54 & 1,36 & 0,79 & \\
\hline Alemania & 2,19 & 1,76 & 1,04 & 1,64 & 1,38 & 1,18 & \\
\hline Italia & 1,18 & 1,10 & 1,28 & 1,18 & 1,10 & 0,75 & \\
\hline EEUU & 2,27 & 1,94 & 2,26 & 1,19 & 1,07 & 2,41 & \\
\hline OCDE 34 & 1,49 & 1,37 & 1,46 & 1,38 & 1,27 & 1,41 & \\
\hline UE-28 & 1,34 & 1,23 & 1,35 & 1,28 & 1,19 & 1,04 & \\
\hline \multicolumn{8}{|c|}{$\begin{array}{l}\text { * CE 2015a, excepto para EEUU. } \\
\text { ** La variación para EEUU es entre 2010-2015 y } 2050 .\end{array}$} \\
\hline
\end{tabular}


de la ratio gasto en pensiones/PIB, tas evaluar los efectos de las últimas reformas realizadas, que OCDE $(2015$, t. 9.5) toma de CE (2015a, tt. II.1.11/II.1.14), agregándole su estimación para el conjunto de la zona. La agregación de las proyecciones de la UE arroja un resultado de estabilidad (todavía superior en la eurozona, cuya ratio $g_{p}$ no varía hasta 2060), aunque la situación es muy diferente entre países. Según estas estimaciones, en 2013 la $g_{p}$ media de la UE era de 11,3 por 100 (y 12,3 por 100 la de la EA). Cinco países superaban esa ratio en más de un 20 por 100: Grecia (16,2 por 100), Italia (15,7 por 100), Francia (14,9 por 100), Austria (13,9 por 100) y Portugal (13,8 por 100).

Los dos primeros redujeron su ratio en 1,9 puntos durante el periodo proyectado; Francia es, después de Croacia, el país que experimentó una mayor reducción (-2,8 puntos); en cambio, Austria aumenta medio punto (situándose en 2060 en el tercer lugar de la UE), y Portugal disminuye 0,7 puntos. Por el contrario, los crecimientos máximos los experimentan dos países que se encontraban en 2013 en torno a la media: Eslovenia (que alcanza también el nivel máximo de 15,3 por 100 , creciendo 3,5 puntos hasta 2060), seguido de Bélgica (con 15,1 por 100 en 2060 y un crecimiento de 3,3 puntos).

Sin embargo, lo más significativo aparece cuando comparamos la situación y las proyecciones realizadas por la CE en los Ageing Reports de 2009, 2012 y 2015, que se sintetizan en el Cuadro 4. En el de 2009 las desviaciones de las ratios $g_{p}$ entre los 27 países de la UE (aunque en el cuadro figura también Noruega y todavía no Croacia) diferían en un tercio del promedio simple y su promedio ponderado se situaba en el 10,1 por 100, según indica el coeficiente de variación y el promedio que aparece en las filas cuarta y segunda contando desde el borde inferior del Cuadro 4. Las proyecciones ese año fueron considerablemente optimistas, como se vería después, aunque ya se preveía que la ratio media $(10,1$ por 100) aumentaría 2,4 pp hasta 2060 y el coeficiente de variación lo haría hasta el 40 por 100. Tres años más tarde la ratio media observada $(12,2$ por 100$)$ ya había crecido todo lo que anteriormente se preveía hasta 2050 (2,1 puntos) aunque la dispersión se había amortiguado hasta el 28 por 100.

Las nuevas proyecciones realizadas en medio de la Gran Recesión estimaron que las reformas que se estaban emprendiendo contendrían el crecimiento del $g_{p}$ hasta avanzar solo 1,9 puntos desde 2010 hasta la fecha final (frente a 2,4 puntos anteriormente). En cambio, las proyecciones realizadas en 2015 , ya plenamente implantadas y evaluadas la últimas reformas, establecieron que en 2060 la $g_{p}$ media caerá dos décimas respecto al año inicial (y la de la eurozona se estabilizará), comprimiéndose la dispersión hasta casi estabilizarse 12 pp por debajo de la estimada en 2009.

El Cuadro 4 contiene tres columnas de variaciones entre el periodo inicial y final de estas proyecciones y dos columnas de diferencias entre ellas (entre 2015 y 2012, en la columna 7, y entre 2015 y 2009, en la 11), que pueden considerarse como indicador del efecto de las mismas, ya que anotan la merma entre la variación del $g_{p}$ a lo largo del periodo proyectado después y antes de tomar en consideración los cambios registrados durante ese sexenio. Además, la ordenación de los países en el cuadro se realiza de acuerdo con la última columna, de mayor a menor intensidad de tales efectos.

En conjunto, el impacto de las reformas reduce en 2,6 pp la previsión acerca de lo que será el aumento del $g_{\mathrm{p}}$ medio de la UE durante el $\triangleright$ 


\section{Álvaro Espina}

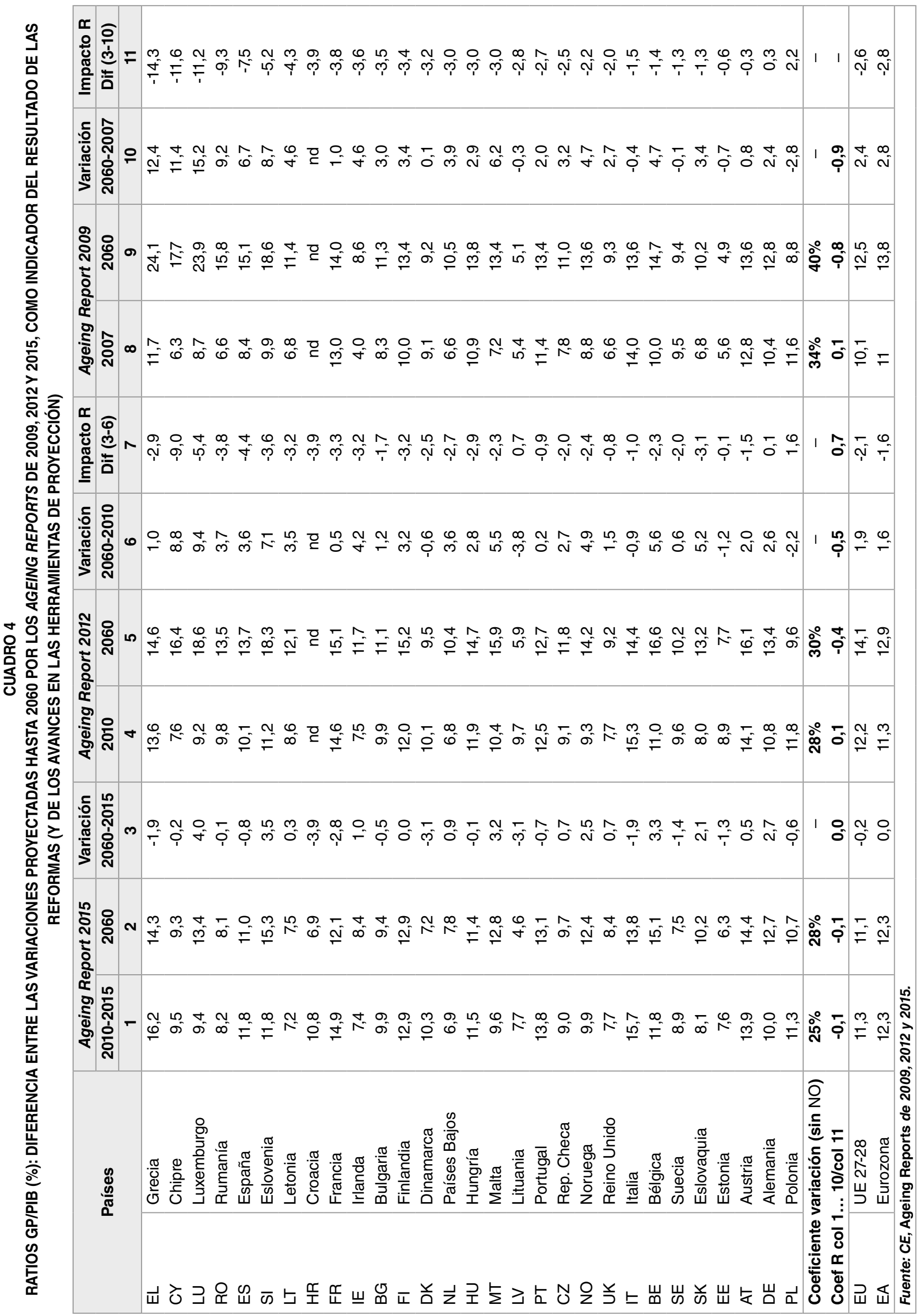


próximo medio siglo (2,8 puntos para la $E A)$, estabilizándolo prácticamente respecto al nivel efectivamente alcanzado en 2015 (año en que se llegó al nivel que en 2009 se preveía llegar en 2030).

Quizás lo más llamativo de la evolución de las tres proyecciones es la compresión a algo más de la mitad del recorrido entre los países con menor y mayor $g_{p}$ proyectado para 2060 , que pasa de 19,2 a 10,7 pp, reduciéndose los niveles máximos desde el 24 por 100 (en donde se situaban Grecia y Luxemburgo) al 14-15 por 100 (en donde, redondeando las cifras, se situarán en 2060 Eslovenia, Bélgica, Grecia, Austria e Italia, que ocupan las dos primeras barras del Gráfico 4).

No cabe duda de la estrecha relación entre esta percepción analítica acerca del crecimiento incontrolado de la $g_{p}$ y la intensa actividad reformadora impulsada desde la UE y llevada a cabo por los países (en algunos casos, como Grecia y Chipre - que se sitúan a la cabeza de la columna 11 del Cuadro 4- por exigencia directa de los programas de ajuste). De hecho, casi el 90 por 100 de la varianza de la columna 11 , que mide el impacto previsto de las reformas, viene explicada por la columna 10 , que mide las previsiones de crecimiento realizadas en 2009 (y el 80 por 100, por la columna 9, que mide los niveles de $g_{p}$ previstos entonces para 2060). Y lo mismo cabría afirmar de la comparación entre las previsiones de 2012 y 2015: si realizásemos la medición del coeficiente $R$ con respecto a la diferencia entre las columnas 3 y 6 , que aparece en la columna 7, la varianza explicada por la columna 6 se situaría en 80 por 100 y la de la columna 5 en 60 por 100. Finalmente, el coeficiente $R$ de la columna 7 (positivo, del 70 por 100) indica que la situación en 2010 ya avanzaba rápidamente en la corrección de los desajustes.

Por lo tanto, la reforma realizada -y la propuesta en Espina (2017c), que mantiene las mismas previsiones de crecimiento total- puede contemplarse también como una forma de aproximación a la mediana de la cifra de $g_{p}$ proyectada a largo plazo para la UE y la EA (Gráfico 4).

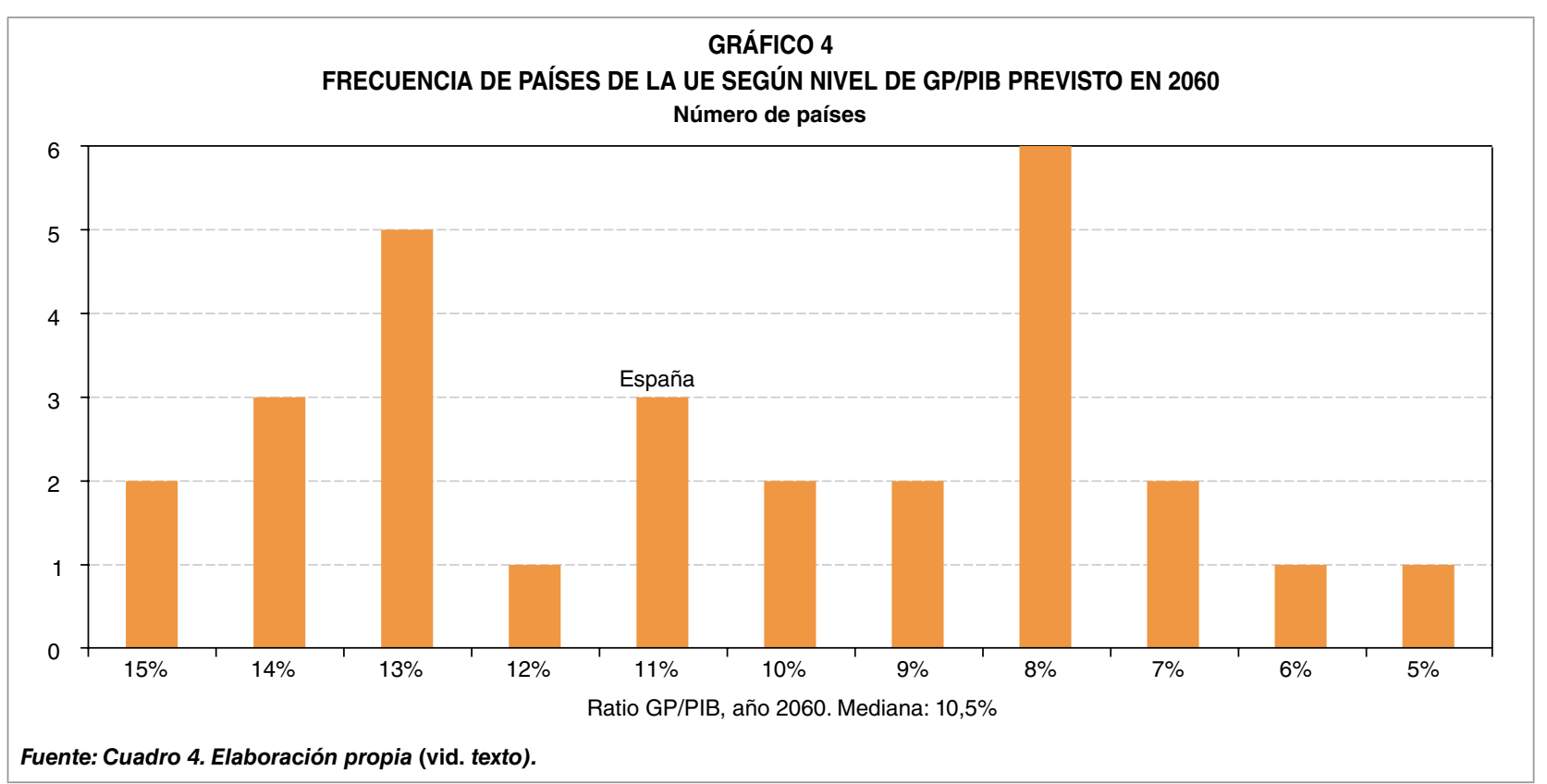


En lo que resta de este trabajo compararemos las medidas propuestas en nuestra reforma con las mejores prácticas vigentes en el conjunto del área, tanto en el segundo como en el tercer pilar de las pensiones, examinando alternativas y medidas para perfeccionar aquellas.

\section{La perspectiva comparada: las mejores prácticas para los principales parámetros del sistema obligatorio de pensiones}

De nuestro inventario de cuatro medidas de reforma la primera a considerar es la edad legal de jubilación prevista para 2060, ya fijada de manera determinista, ya prevista por la proyección demográfica cuando tal edad se encuentra asociada al avance de la esperanza de vida. En el Gráfico 5 puede observarse la tabla de frecuencias o número de países para cada edad individual entre 65 y 73 años (redondeando las cifras intermedias). Sorprende que Dinamarca y Países Bajos, los dos países con edades máximas previstas de jubilación $(72,5$ y 71,5$)$ se encuentren en la zona baja de $g_{p}$ proyectados en el Cuadro 4, con ratios del 7 por 100 y el 8 por 100 (o quizás esa sea una de las razones que lo explican, ya que en ambos casos la edad actual se sitúa en 65 años y se prevé un aumento de más de un año cada decenio).

Por el contrario, los dos países que prevén establecer la edad en 70 años (Grecia e Italia) se sitúan en el extremo opuesto de la segunda columna del Cuadro 4 , con ratios $g_{p}$ proyectados que duplican los de aquellos dos países. La reforma de 2013 sitúa a España en la zona baja de la tabla, aunque a dos años de distancia de la edad mínima (que en este caso es también la moda dentro de la UE). Como es sabido, para hacer frente a las consecuencias del aumento de la esperanza de vida sobre el equilibrio de los sistemas de pensiones los $\triangleright$

GRÁFICO 5

NÚMERO DE PAÍSES DE LA UE SEGÚN EDAD LEGAL DE JUBILACIÓN (HOMBRES, 2060)

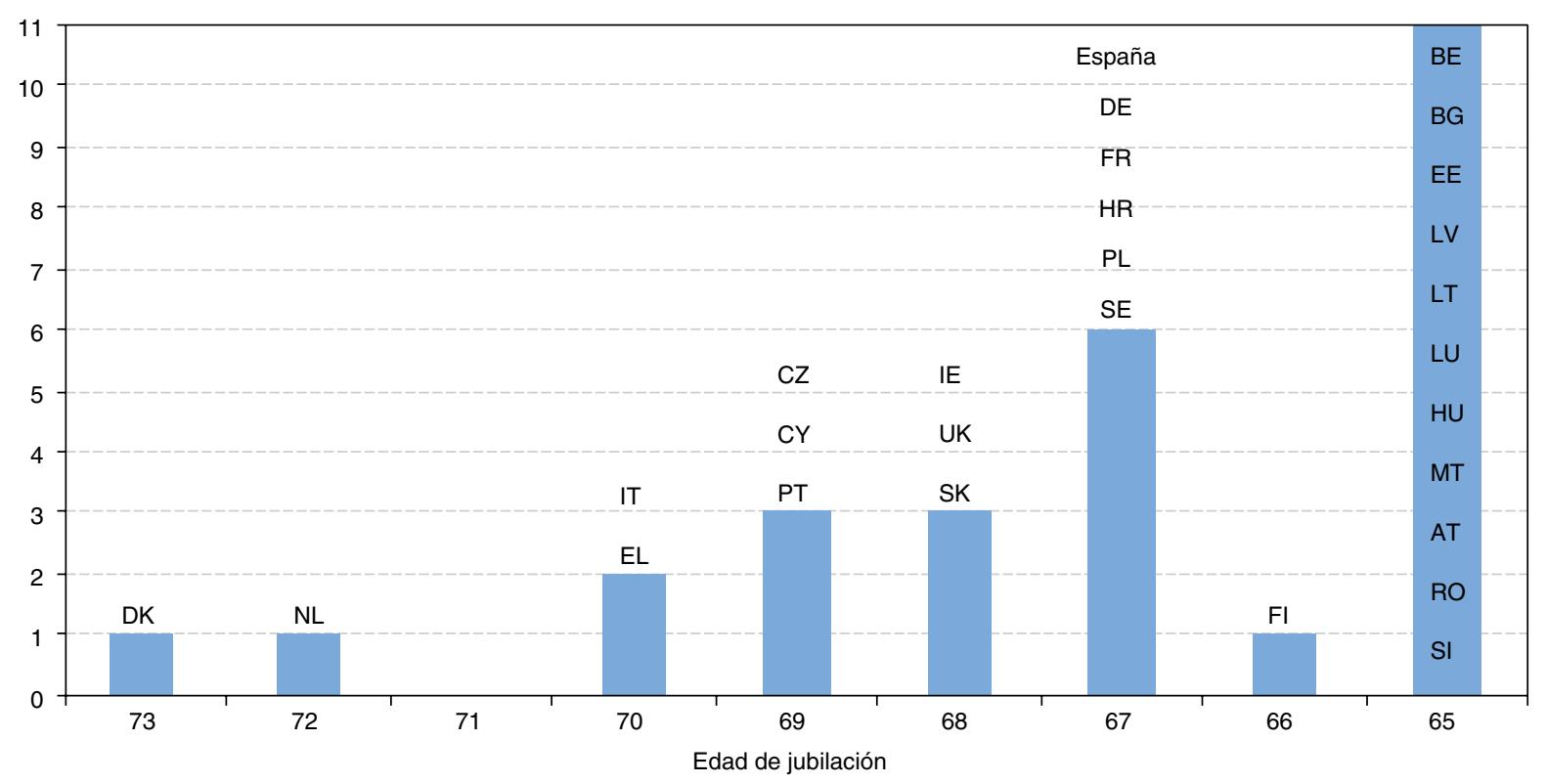

Fuente: CE (2015a), tabla II.1.4. Elaboración propia. 


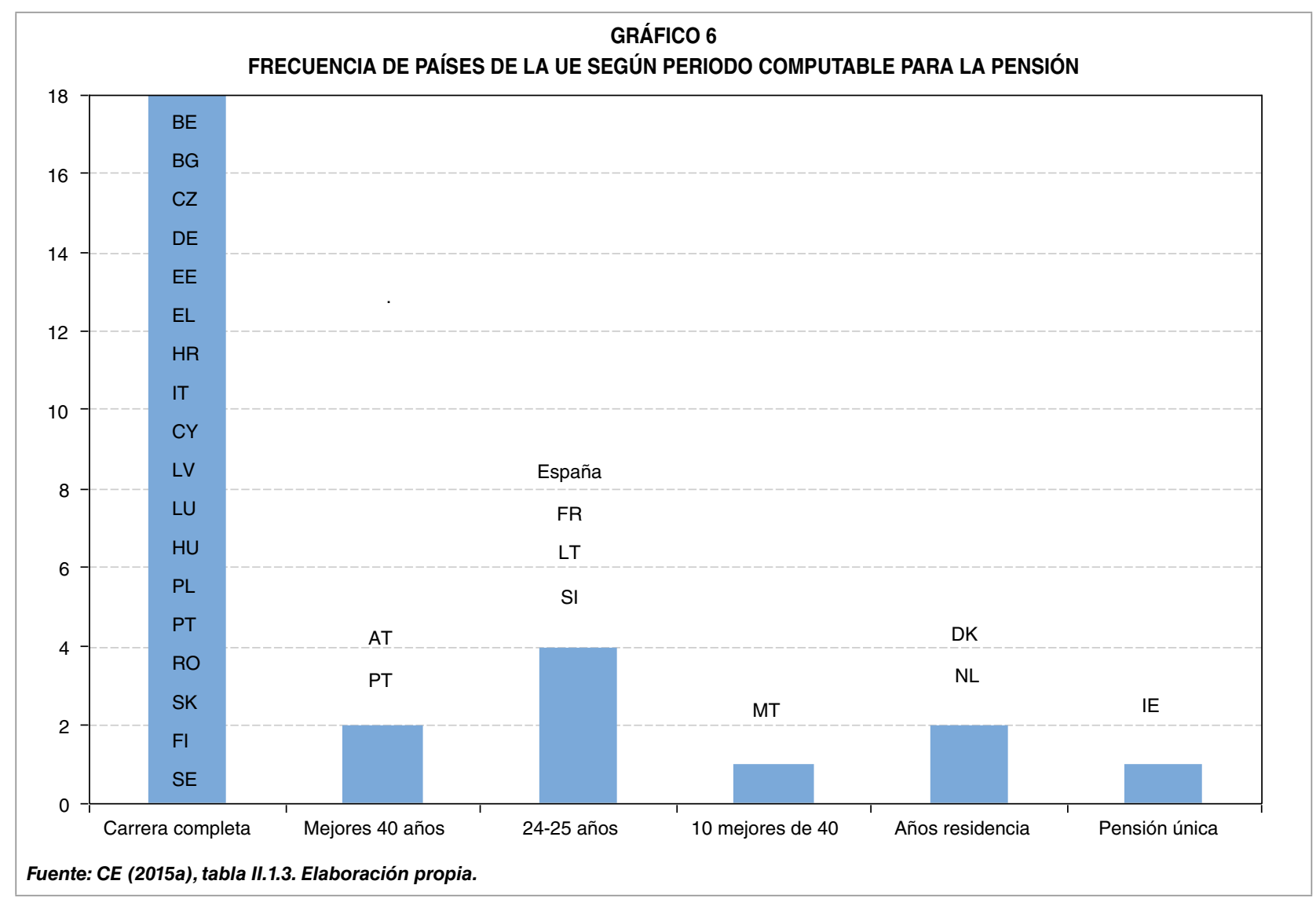

países han optado por una de las dos vías disponibles: ajustar la edad legal o ajustar la cuantía de la pensión a la evolución de esa variable demográfica (Meneu, Devesa et al., 2017).

En el caso español, la reforma de 2011 eligió la primera opción, pero deteniendo el ajuste momentáneamente en 2027 (para reconsiderarlo después), y la reforma de 2013 eligió la segunda, adaptando la cuantía de la pensión inicial a tal evolución a través del factor de sostenibilidad (FS). En Espina (2017c) se argumentó que esta elección fue desacertada y de lógica muy difícil de defender, al menos hasta 2027, en que el aumento de la edad absorberá por completo el de la esperanza. Además, su impacto añade incertidumbre a las perspectivas de evolución del poder adquisitivo, que quedarían despejadas suprimiendo el FS y sustituyéndolo por una disminución paulatina de la ratio de reposición inicial (la segunda medida de nuestra reforma). Por todo ello, pese a no ser hasta ahora mayoritario, seguimos optando en principio por la prolongación de la edad de jubilación hasta alcanzar los setenta años en 2063, ofreciendo alternativas optativas que se explican más adelante.

$Y$ es que la edad de jubilación (tanto legal como efectiva) guarda una estrecha relación con los restantes parámetros utilizados para calcular la pensión inicial. La primera variable relevante es el periodo de tiempo computado en cada país para calcular la base de cotización que corresponde a cada pensionista.

El Gráfico 6 ofrece una visión panorámica de la duración de este periodo en los 28 países de la UE. Se observa que el cómputo de la carrera completa de cotización resulta absolutamente dominante (18 países, que se $\triangleright$ 
elevan a 22 si se agregan los dos países que computan 40 años y los otros dos que computan la totalidad de años de residencia). Exceptuando Irlanda, que ofrece una pensión única, solo Malta computa un número menor de años que el grupo de cuatro países que limitan el periodo a 24-25 años. Francia y Lituania computan los 25 años con mayor cotización de toda la carrera, y Eslovenia los mejores 24 años (con la peculiaridad de que en este caso deben ser consecutivos).

Solo España computa los últimos 25 años de cotización (y eso, a partir de 2022). En principio tal cosa pudo deberse a la voluntad de favorecer al pensionista, ya que tradicionalmente las carreras habían sido ascendentes y los últimos años eran los de mayor cotización, pero hoy eso ya no es necesariamente así. Además, las interrupciones de cotización a la largo de la carrera -ya sea por causa de la crianza de hijos, ya por la de reciclaje profesional o por desempleo de larga duración, episodios que cuentan con otros mecanismos de compensación- ${ }^{14}$ se distribuyen de forma errática, por lo que la protección se consigue mejor computando toda la carrera o, al menos, estableciendo como periodo de cómputo aquellos de mayor cotización, independientemente del momento en que se produzcan ${ }^{15}$.

El número de años de cotización computables interactúa con la pauta por la que se accede a la pensión plena o se modula su cuantía, denominada «índice anual de acumulación o

\footnotetext{
14 Véase al respecto «How incomplete careers affect pension entitlements", capítulo 3 de OECD (2015). Naturalmente, en los países con menores periodos de cómputo las carreras incompletas afectan mucho menos a la disminución de la ratio de reposición: España y Francia se encuentran entre los países con menor merma por esa causa (OECD 2017b, fig. 2.21, p. 42), disponible en: http://dx.doi. org/10.1787/888933566438

15 El estudio más completo disponible para el caso español, realizado a partir de la construcción de historias laborales virtuales, también aconseja hacerlo en aras de mejorar la equidad intrageneracional, ya que la desviación típica de las rentas salariales suele aumentar a partir de los cincuenta años. Véase Jimeno (2003).
}

devengo del derecho a la pensión» (en inglés, accrual rate), que es precisamente el algoritmo que transforma la carrera de cotización durante la vida laboral en derecho a pensión.

No todos los países utilizan algoritmos explícitos para hacerlo. Por ejemplo, Alemania y algún otro país utilizan un sistema de acumulación de puntos, calculados tomando en consideración distintas variables -entre ellas el factor de sostenibilidad-, cuya equivalencia en valor efectivo se determina anualmente, por lo que no es comparable con los índices de acumulación o devengo, como tampoco lo es en países con pensión única o no relacionada con los ingresos, ni allí donde la pensión se fija discrecionalmente. Sin embargo, 19 países de la UE emplean aquel sistema de devengo, y, aunque no necesariamente dispongan de una cifra única en cada uno de ellos, los estudios de CE (2015b) permiten estimar las tasas de acumulación empleadas por las pensiones de vejez, que se han llevado al Gráfico 7.

En el gráfico sobresale el caso de España, ya que, al acumularse el 50 por 100 de la base reguladora durante los primeros quince años y el otro 50 por 100 en los 22 años siguientes, el promedio resultante es de 2,7 puntos por año, muy por encima del caso de Portugal, con tasas de devengo entre 2 y 2,3 por 100 (dependiendo del número de años registrados). La moda de los 19 países, redondeando las cifras como se hace en el gráfico, es 1,5 por 100, y la media, 1,556 por 100 , por lo que la accrual rate de España es de un 73 por 100 superior a esta última.

Puede observarse que la ratio de reposición legal a la edad de jubilación y la tasa de acumulación a lo largo del periodo de cotización (o tasa de devengo), combinada con el periodo efectivamente computado, guardan entre sí una relación de sustitución, como puede $\triangleright$ 


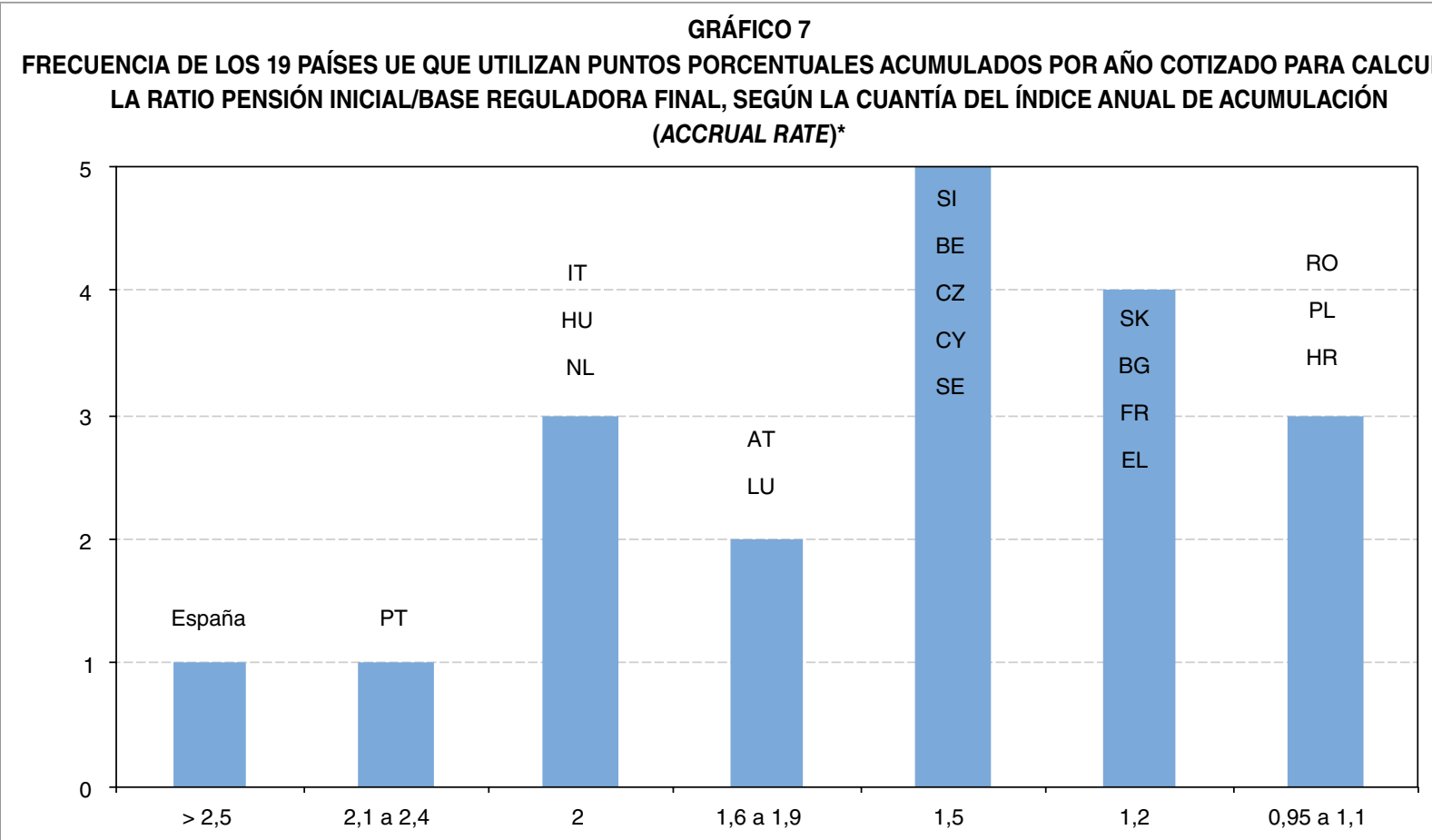

*Véanse las fichas por países en el Anexo 2 de CE (2015b), Parte II, p. 159 y ss., de donde se extraen las cifras del gráfico. Cuando existen varias, generalmente guardan una relación estrecha y se han promediado.

Fuente: CE (2015b), Parte II, p. 159 y ss. Elaboración propia (vid. nota 15).

\section{CUADRO 5}

CARRERA COMPUTABLE, TASA DE DEVENGOY TASA LEGAL DE REPOSICIÓN (SIMULACIÓN)

\begin{tabular}{|l|c|c|c|c|c|c|c|}
\hline \multicolumn{1}{|c|}{ Año } & $\mathbf{2 0 1 7}$ & $\mathbf{2 0 2 0}$ & $\mathbf{2 0 3 0}$ & $\mathbf{2 0 4 0}$ & $\mathbf{2 0 5 0}$ & $\mathbf{2 0 6 0}$ & $\mathbf{2 0 6 6}$ \\
\hline Carrera completa (años) & 37,4 & 37,8 & 39,4 & 41,0 & 42,5 & 44,1 & 45,0 \\
\hline Tasa devengo (puntos \%) & 2,703 & 2,632 & 2,398 & 2,164 & 1,930 & 1,696 & 1,556 \\
\hline Tasa legal reposición (\%) & 100,6 & 99,6 & 94,5 & 88,6 & 82,1 & 74,8 & 70,0 \\
\hline \multicolumn{1}{|c|}{ Variación anual } & & $\mathbf{2 0 1 7 - 2 0 2 0}$ & $\mathbf{2 0 2 0 - 2 0 3 0}$ & $\mathbf{2 0 3 0 - 2 0 4 0}$ & $\mathbf{2 0 4 0 - 2 0 5 0}$ & $\mathbf{2 0 5 0 - 2 0 6 0}$ & $\mathbf{2 0 6 0 - 2 0 6 6}$ \\
\hline Años & & 0,156 & 0,156 & 0,156 & 0,156 & 0,156 & 0,156 \\
\hline Puntos & & $-0,023$ & $-0,023$ & $-0,023$ & $-0,023$ & $-0,023$ & $-0,023$ \\
\hline Puntos porcentuales & & $-0,325$ & $-0,512$ & $-0,585$ & $-0,658$ & $-0,731$ & $-0,789$ \\
\hline Fuente: elaboración propia. & & & & & &
\end{tabular}

observarse en el Cuadro 5, en el que se simula en la primera fila una posible evolución de la carrera computable en España, desde los 37 años computados actualmente (aunque en los cálculos se han tomado como punto de partida los 37,22 en que se situaba en 2016 la carrera media del sistema, por lo que la tasa de reposición en 2017 supera el 100 por 100) hasta 45 años en 2066 (como consecuencia de la prolongación de la edad legal y de los incentivos para realizar una carrera más larga). En la segunda fila se dibuja una posible senda de la tasa de devengo actual (situada en media en 2,703 , sin tomar en consideración la asimetría legal existente entre los 15 primeros años de carrera y los 22 subsiguientes) hasta la tasa media actual de la UE, que se fijaría como objetivo a alcanzar en 2066.

Puede apreciarse que la combinación por producto entre esos dos procesos da como $D$ 


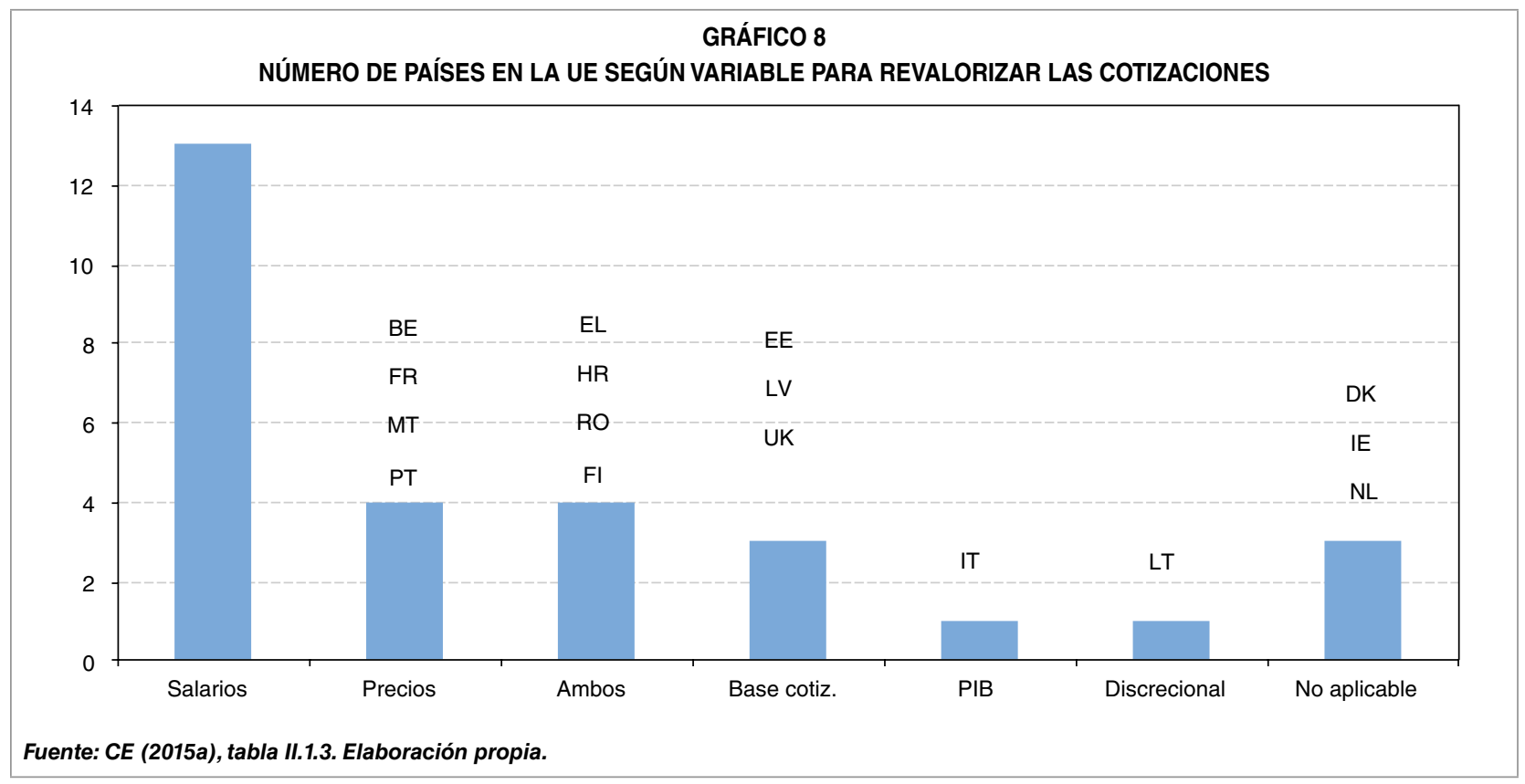

resultado una evolución de la tasa legal de reposición muy similar a la que se propone en nuestra reforma, por lo que podría considerarse como alternativa a la segunda medida enunciada en la introducción a este trabajo. Es más, una vez alcanzado el nivel de 70 por 100, podría liberalizarse la edad legal obligatoria y dejarla en la cifra establecida en 2011, ya que a partir de 2066, en caso de no prolongarse esa edad voluntariamente, la tasa de reposición conseguida disminuiría, aumentando de ese modo las oportunidades de elección entre lo uno y lo otro para los nuevos jubilados. La parte inferior del Cuadro 5 indica que con la senda propuesta para la tasa de devengo (que disminuiría en 0,023 puntos cada año), para alcanzar una tasa de reposición del 70 por 100 en 2066 la carrera de cotización efectiva debería elevarse anualmente en 0,156 años hasta esa fecha (o sea, 1,87 meses).

La otra variable que determina el significado práctico de la ratio de sustitución es el algoritmo para calcular la base reguladora a la que se aplica, dependiente de la carrera de cotización computable a estos efectos (distinta de la carrera para la tasa de devengo). Como ya se dijo, actualmente en España este periodo se encuentra en fase de aumento (de 20 años en 2017 y se elevará anualmente en doce meses hasta alcanzar los 25 años que aparecen en el Gráfico 6 en el año 2022, pasando de 240 meses a 300) ${ }^{16}$.

Para pasar a computar la carrera completa, como ocurre en la inmensa mayoría de países de la UE (Gráfico 6), debería incrementarse anualmente en doce meses el periodo de cómputo, de modo que los 45 años se alcanzarían en 2042 (con ratio 540/630).

Para la revalorización de las cotizaciones (que en España se denomina actualización) la mayoría de los países (13) utilizan los salarios, que es donde los servicios de la CE sitúan a España (Gráfico 8). Esto es un error, ya que $\triangleright$

16 Como la pensión anual se percibe en catorce pagas, las cifras de cotización computables para doce meses se dividen por catorce: en 2017 se aplica la ratio 240/280 y en 2022 la ratio llega a 300/350: http://www.seg-social.es/Internet_1/Trabajadores/PrestacionesPension 10935/Jubilacion/RegimenGeneral/Jubilacionordinaria/Cuantia/index. htm\#6159. En esta página se explican todos los factores que inciden sobre el algoritmo. 


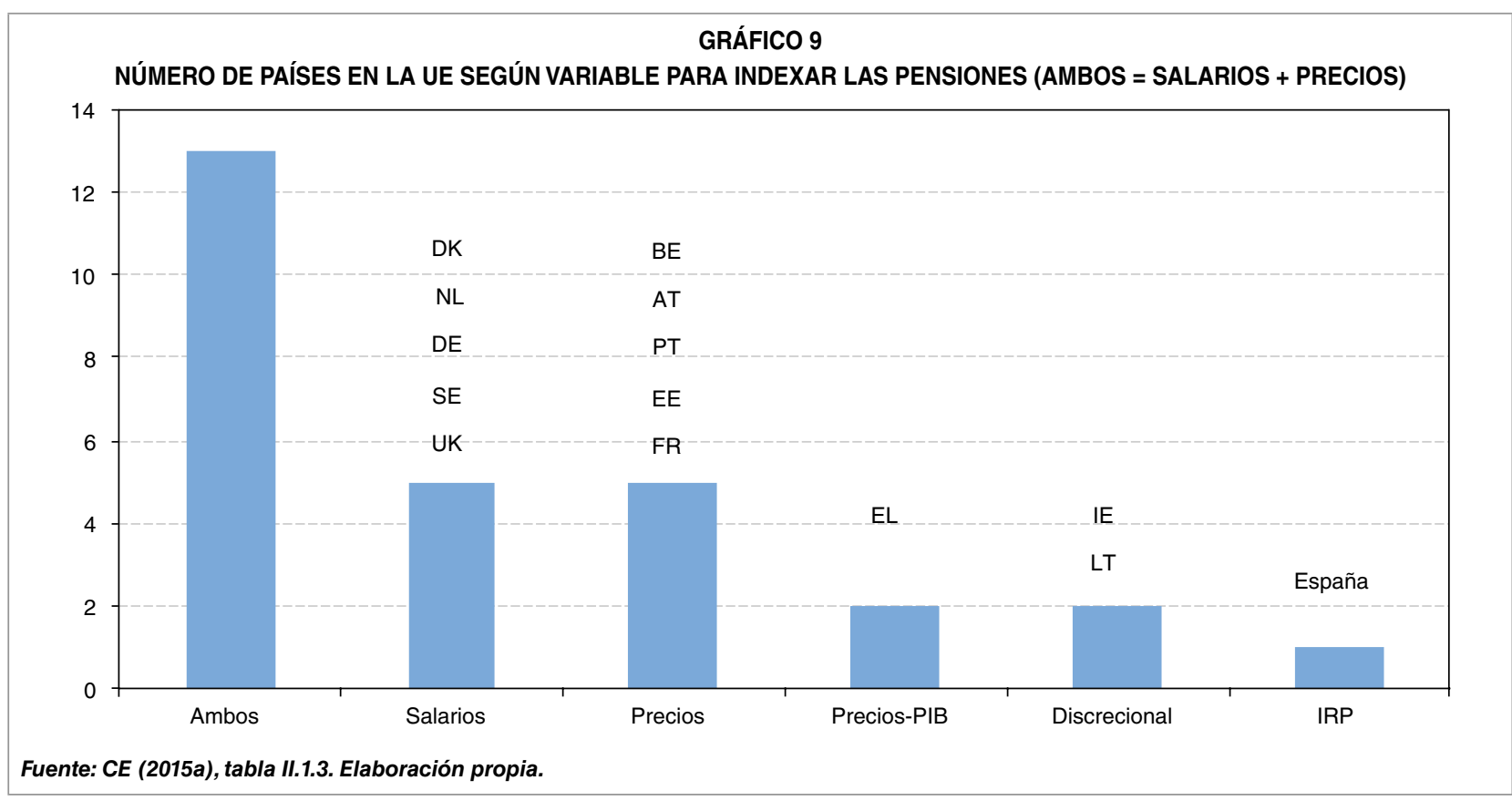

nuestro país actualiza las bases de cotización (excepto las de los últimos 24 meses, que se computan a su valor nominal, lo que puede explicar el error) revalorizándolas con el IPC, como sucede en Bélgica, Francia, Portugal y Malta. No parece necesario sugerir cambios en este procedimiento, ya que revalorizar con el índice de salarios implica elevar el IPC con el crecimiento del salario real, $y$, en caso de crecer este como la productividad, tal cosa obligaría a reducir todavía más la ratio de reposición para recuperar el equilibrio en que se basan las proyecciones que sirven para diseñar la reforma propuesta.

Respecto a la indexación de las pensiones para el mantenimiento de su poder adquisitivo a lo largo de la vida pensionable, el Gráfico 9 indica que la moda en los países UE es emplear un indicador mixto entre los salarios y el IPC (ponderándolos en distinta medida). Tampoco aquí deben introducirse cambios, por las mismas razones señaladas para la revalorización, aunque en la propuesta que sigue se permite una opción condicionada entre el IRP y el IPC.

\section{Una propuesta alternativa de reforma basada en las mejores prácticas de los sistemas obligatorios de pensiones}

De todo el epígrafe anterior puede colegirse que existen procedimientos alternativos para llevar a cabo la reducción de la ratio de reposición que figura en la propuesta de reforma sintetizada al comienzo de este trabajo y que, persiguiendo los mismos objetivos, producen al mismo tiempo resultados más beneficiosos en lo que se refiere a la equidad intrageneracional del sistema de pensiones, lo que seguramente explica que tales procedimientos se correspondan con las mejores y más extendidas prácticas de los otros países europeos. En síntesis, la adopción de las mismas significaría:

a. Tomar la carrera completa de cotización como periodo de cómputo, tanto para calcular la base reguladora de la pensión como para llevar a cabo la acumulación de puntos porcentuales que sirve para $\triangleright$ 
determinar la tasa legal de reposición aplicable a la base reguladora de la pensión inicial.

b. Establecer como objetivo un índice de acumulación (accrual rate) de 1,556 puntos al año, de manera homogénea a lo largo de toda la carrera de cotización. De este modo, en el momento de aplicarse ese índice con 45 años de carrera se alcanzaría la ratio legal de reposición del 70 por 100. Para bonificar adicionalmente las carreras más largas, a partir de 45 años podría reducirse el índice al 1 por 100, estableciendo un límite máximo del 75 por 100 para aquella ratio. Además, para reducir el impacto del aumento por la mayor volatilidad de los empleos, convendría computar en la acumulación de la tasa de devengo los años de desempleo una vez agotadas las prestaciones, mientras el desempleado se mantenga en búsqueda activa de empleo - computada esta de manera rigurosa-, por un periodo máximo acumulado de ocho años, cotizando el SEPE (Servicio Público de Empleo Estatal) por el trabajador sobre la base del IPREM (Indicador Público de Renta de Efectos Múltiples).

c. Mantener la fórmula aplicada hasta ahora para la actualización de las cotizaciones realizadas a lo largo de la vida activa con el IPC, excluyendo las dos últimas anualidades (o 24 meses). En lo que se refiere a la indexación anual de las pensiones, mantener la senda de revalorización con pérdida decreciente del poder adquisitivo hasta el momento en que los puntos a y b sean de plena aplicación, adoptando el IPC a partir de entonces.

d. Sin embargo, los puntos a y b pueden llevarse a cabo en un solo momento o bien a lo largo de un periodo transitorio, ofreciendo la posibilidad de que sea el pensionista quien elija entre las dos opciones, con las siguientes condiciones:

$i$. La opción de la reforma completamente gradual implicaría reducir anualmente a partir de 2018 la tasa de devengo en 0,023 puntos, partiendo de la tasa actual media situada en 2,703 . Se aumentaría en dos meses por año el periodo de cómputo y en un año el empleado para calcular la base reguladora de la pensión inicial. De este modo, el primero alcanzaría los 45 años en 2060, situándose la tasa anual en 1,556, y el segundo en 2047. Sería de aplicación en este caso la prolongación de la edad legal de jubilación hasta 70 años y la pérdida de poder adquisitivo de la pensión programada, aunque ambas cosas solo hasta 2060 , revalorizándose con el IPC a partir de entonces, pudiendo el jubilado hacerlo a partir de 67 años.

ii. La segunda opción permitiría al nuevo pensionista optar, en el momento de calcularse su pensión inicial, por la aplicación de los periodos de cómputo y el índice de acumulación correspondientes no a ese año, sino al central de su esperanza de vida en jubilación. Como el promedio de esta última es de 22 años, el de referencia para los índices sería el resultado de aumentar en 11 el año de jubilación. En tal caso se le garantizaría que el índice de revalorización anual aplicado a su pensión sería el IPC. Adicionalmente, desde el momento en que la tasa anual sea de 1,556 y los periodos $D$ 
mínimos de cómputo, de 45 años, dejaría de aplicarse la prolongación de la edad obligatoria, manteniéndose en 67 años, pudiendo el futuro pensionista prorrogarla hasta alcanzar una ratio de reposición inicial máxima del 75 por 100.

iii. Al elegir ii en lugar de $i$, el nuevo pensionista estaría optando por disponer inicialmente de una pensión inferior a la que le correspondería de haberse acogido a la reforma completamente gradual, pero manteniendo el poder adquisitivo a lo largo de toda su vida y disponiendo de mayores opciones. En promedio, las dos vías tienen el mismo coste, pero la última cumple el objetivo de mantenimiento constante del poder adquisitivo del pensionista, una vez franqueado el umbral entre vida activa y jubilación, mientras que la primera favorece al menos longevo pero eleva el riesgo de pobreza durante los últimos años de vida del más longevo (salvaguardado solo a través del complemento para mínimos) ${ }^{17}$, en caso de que no haya ahorrado durante su vida activa y sus primeros años como pensionista.

En cualquier caso, la reforma implica que al término del proceso la tasa inicial de reposición pensión/base reguladora quedará reducida un 30 por 100 (un 25 por 100 para las carreras máximas). Esta es una de las reformas más drásticas de entre las realizadas recientemente en los países desarrollados, como se observaba también en el Cuadro 5. Para que tal cosa

17 Según OECD (2017b, f. 1.23), España es el país con menor tasa de pobreza en los adultos que viven solos con edades de 80 y más años: http://dx.doi.org/10.1787/888933566476 resulte asimilable de forma duradera por la población es preciso facilitar e impulsar el desarrollo del ahorro privado para la pensión, de carácter voluntario pero en régimen de libertad (aunque subsidiada), edificando rápidamente el tercer pilar de los sistema de ahorro-pensión, como han venido haciendo la mayoría de países que nos han precedido en este tipo de reformas.

\section{Las políticas públicas y los sistemas privados de pensiones: el tercer pilar}

Históricamente se han empleado también modalidades de ahorro privado con carácter obligatorio, que bajo la tipificación WB-OECD se incluyen en el segundo pilar, no en el tercero. El propósito de tales medidas parece haber sido el de cumplir el objetivo de replegar nominalmente al Estado en el cumplimiento de los objetivos de bienestar y, al mismo tiempo, impulsar la capitalización de los fondos de pensión, por contraposición a los mecanismos de reparto, algo que podría conseguirse igualmente favoreciendo la prolongación voluntaria de la edad de jubilación o el trabajo a tiempo parcial de los jubilados (Ameriks, 2017).

La Gran Recesión ha puesto en duda la bondad de las estimaciones que se habían venido realizando acerca de los diferenciales de rentabilidad a largo plazo entre unos y otros y ha evidenciado también que el riesgo privado y el riesgo público son sustituibles en esta materia (Ebbinghaus, 2015), aunque -en caso de fuerte acumulación- el segundo pueda ejercer cierto influjo perjudicial para la prima de riesgo del país en momentos de crisis financieras. En este epígrafe se analiza el panorama comparado de los sistemas privados de $\triangle$ 


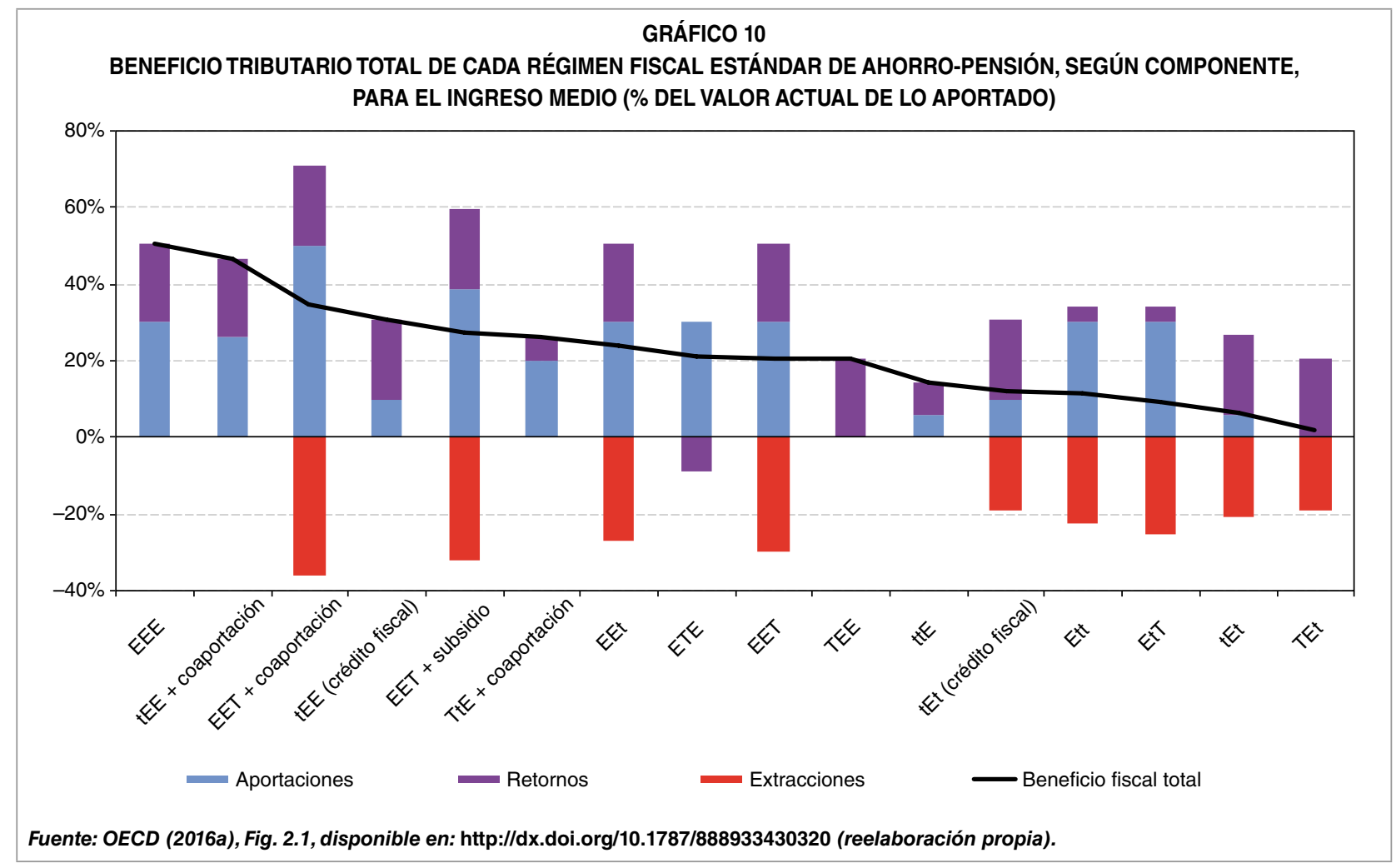

de la zona). En tercer lugar se encuentran los dos sistemas que eximen dos de las fases pero en los que este complemento se hace con crédito fiscal o con un subsidio de tarifa única (el primero por valor de un 10 por 100 de las aportaciones que no excedan de 7.500 euros/año, y el segundo equivalente a una coaportación aplicada al límite máximo cuando esta asciende al 5 por 100 del salario, minorándose a prorrata en caso de aportación inferior). La coaportación compensa también en los sistemas que gravan en distinta medida las dos primeras fases, por lo que el modelo ocupa el sexto lugar, con un 50 por 100 de los beneficios del caso máximo ${ }^{18}$. Los cuatro casos de intensidad media son aquellos que eximen dos fases y gravan solo una, cuyo beneficio en tres de los

18 Obsérvese que la principal diferencia entre exención y crédito fiscal, por un lado, y coaportaciones o subsidios, por otro, es que en el primer caso el gasto fiscal incurrido no figura explícitamente en el presupuesto, mientras que en el segundo sí, al menos en el presupuesto liquidado, por lo que resulta más transparente. cuales -en que la fase gravada resulta totales el 21 por 100 del valor actual de lo aportado, que es el aplicado en España, cuyo sistema grava las retiradas.

Se observa, sin embargo, que en el modelo estandarizado la intensidad del beneficio fiscal obtenido por los titulares en esos tres sistemas resulta independiente de cuál sea la fase gravada y cuáles dos no lo sean (y lo mismo ocurre cuando existen dos fases gravadas y una exenta) ${ }^{19}$. En realidad, es más sencillo el que grava solo las aportaciones (10. ${ }^{-}$barra), puesto que reserva los mayores beneficios para el momento en que se dispone de lo aportado y del flujo de retornos, proporcionando un beneficio medio similar a los anteriores. Sin embargo, los regímenes no son neutrales en cuanto a la distribución del beneficio fiscal a lo largo de la $\triangleright$

19 Una forma de cálculo sencilla se presenta en OECD (2016a, t. 2.1) en que el tipo de descuento es igual a la tasa de retorno y las aportaciones se gravan a la misma tasa que las retiradas. 
GRÁFICO 11

BENEFICIO TRIBUTARIO TOTAL EN EL RÉGIMEN FISCAL DE AHORRO-PENSIÓN EET + SUBSIDIO POR NIVELES DE INGRESOS (EN \% DEL VALOR ACTUAL DE LO APORTADO)

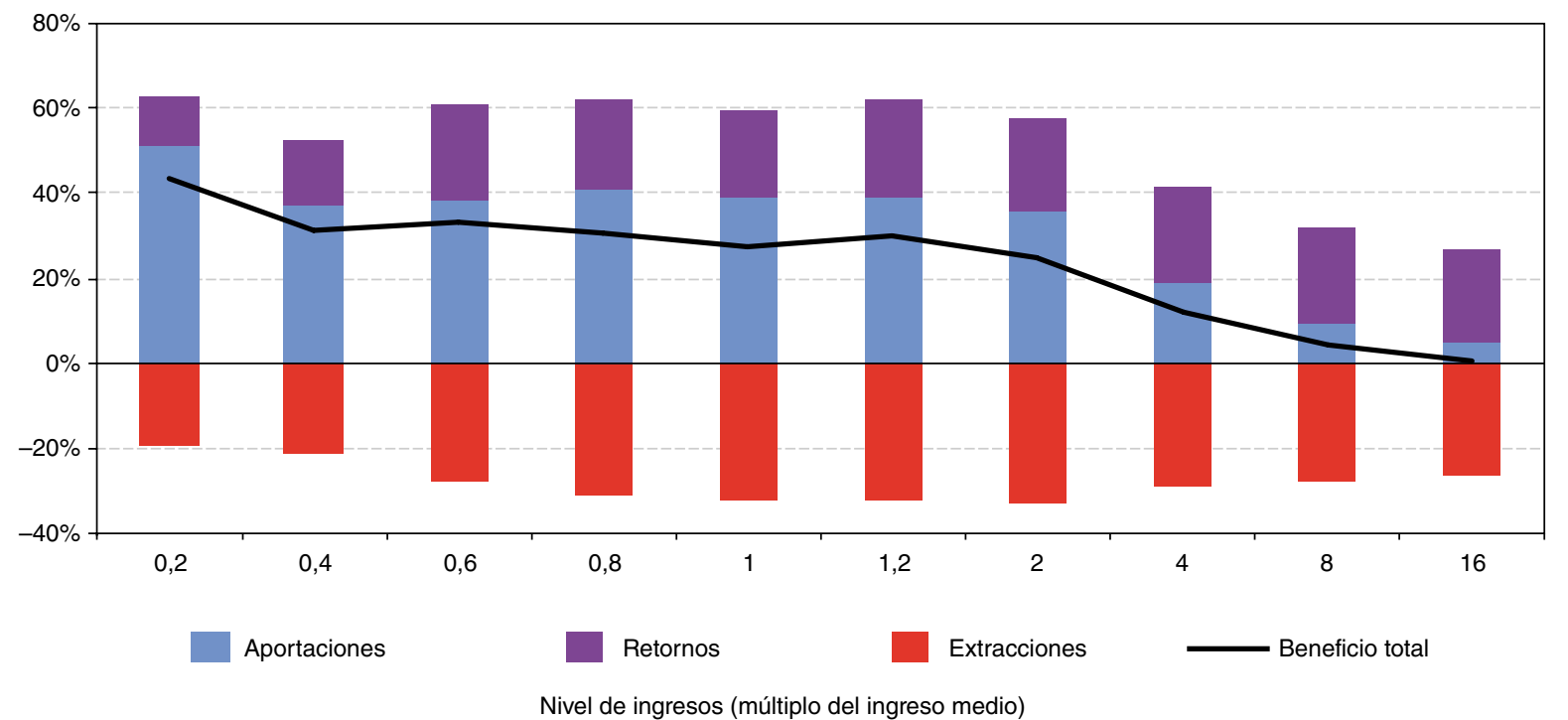

Fuente: OECD (2016a), Fig. 2.2, disponible en: http://dx.doi.org/10.1787/888933430331, (reelaboración propia).

escala de rentas y ese sistema perjudica claramente a quienes se hallan por debajo del 50 por 100 del ingreso medio.

En cambio, los sistemas que eximen de tributación a las tres fases, o a las dos primeras -el español entre ellos-, benefician en principio más a toda la zona de ingresos medios, en perjuicio de los dos extremos, aunque esto puede corregirse para la zona de ingresos más bajos a través de un subsidio, que puede revertir completamente tal desventaja, como se observa en el Gráfico 11. En el mismo se representa el beneficio tributario total obtenido en el sistema EET complementado con un subsidio -equivalente al 1 por 100 del salario medio (cuando el beneficiario aporta el 5 por 100 de su salario, minorándose proporcionalmente en caso de aportación menor) - para seis quintiles (entre 0,2 y 1,2 veces el ingreso medio) y para los múltiplos 2, 4, 8 y 16 del mismo ${ }^{20}$.

20 Para construir los sistemas estandarizados, OCDE (2016a, p. 75) emplea una escala de progresividad fiscal con cinco tramos: $0 \%, 14 \%$, $30 \%, 41 \%$ y $45 \%$, cuyas transiciones se sitúan en bases imponibles de
De todos los modelos estandarizados por la OCDE este es el más equitativo, por su progresividad, ya que otorga un beneficio tributario equivalente aproximadamente a un tercio del valor actual de lo aportado para los tramos entre 0,4 y 1,2 de ingresos medios, elevándolo diez puntos en el tramo inferior y reduciéndolo desde la cuarta parte, en el tramo que duplica al nivel medio, hasta dejarlo en el 1 por 100 en el tramo superior (con múltiplo 16). Esta técnica fiscal permite corregir la tendencia a la regresividad que afecta a las bonificaciones fiscales del resto de los sistemas voluntarios de pensiones del tercer pilar (OECD, 2017b, p. 59).

En cualquier caso, lo que determina el nivel concreto de beneficio fiscal en cada país no es el sistema estandarizado empleado, sino los parámetros concretos que se aplican en cada caso, combinados con su estructura fiscal. $\triangleright$

$9.700 €, 26.791 €, 71.826 €, 152.108 €$. Pro-memoria: para España, en 2016 , los cinco tramos son: $19 \%, 24 \%, 30 \%, 37 \%$ y $45 \%$, con transiciones en $12.450 €, 20.200 €, 35.200 €$ y $60.000 €$. Obsérvese la diferencia en los dos tramos más bajos. 


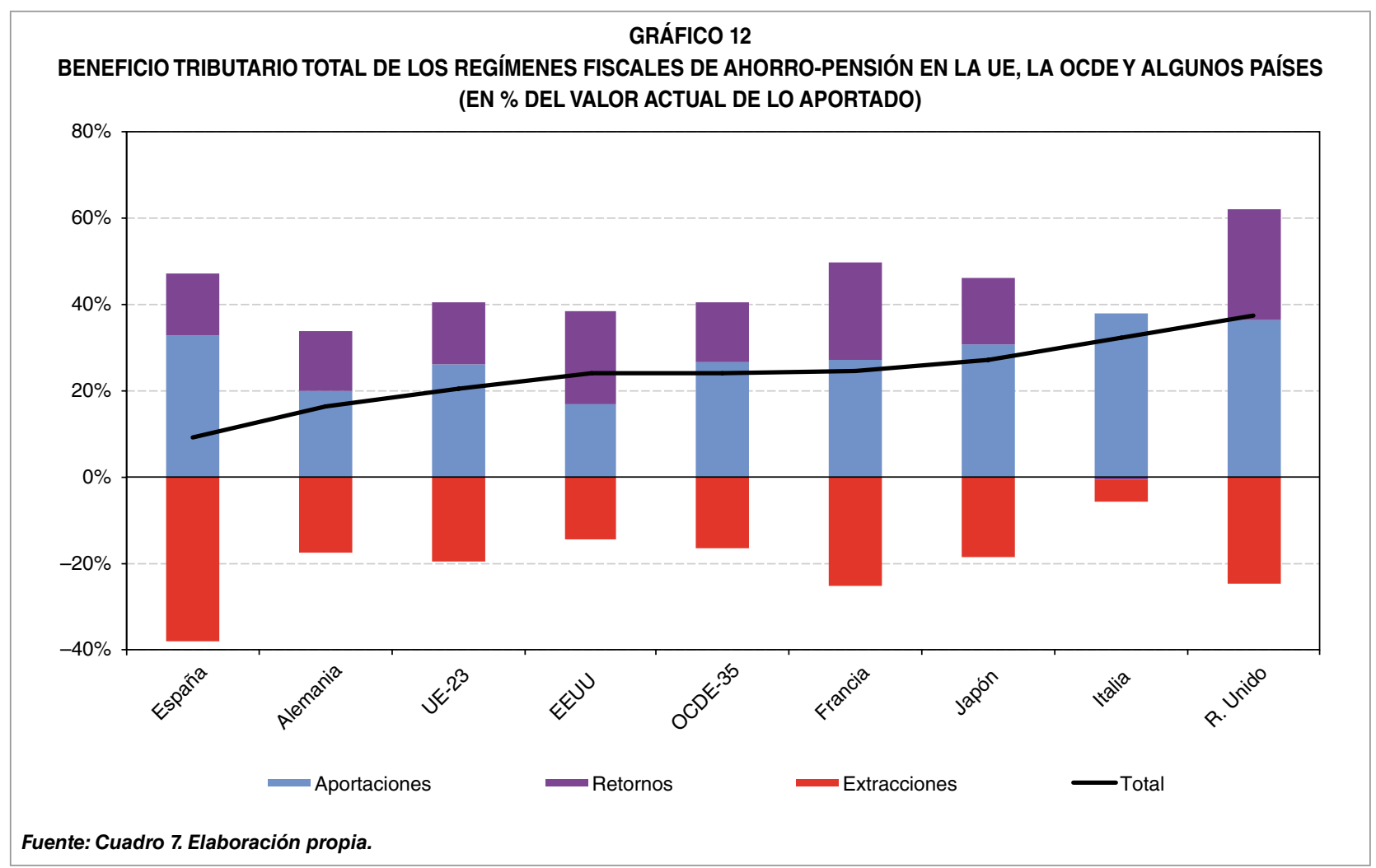

la edad, y el de aportaciones para el cónyuge se elevó a 2.500 euros. En cambio, las prestaciones (o retiradas, en terminología OCDE) se gravan con la escala progresiva del rendimiento del trabajo, una vez agregados los otros ingresos (antes de 2007 las retiradas en forma de capital tuvieron una reducción de la base imponible del 40 por 100 , que se mantiene en forma transitoria para lo aportado hasta esa fecha).

El Cuadro 8 presenta el estado actual de la inversión en fondos de pensiones para los mayores países y agrupaciones relevantes, tanto el stock, en porcentaje del PIB, como el flujo durante el último decenio, con las tasas de crecimiento de ese stock medido en forma relativa y absoluta, además de la tasa real de retorno obtenida en cada caso. España sobresale porque, situándose en la zona baja del volumen de inversión en relación con las medias de la UE y la OCDE (que triplica con creces la de
España), durante el periodo en que estuvo vigente el sistema anterior las aportaciones crecieron a un ritmo exiguo, similar al de EEUU (cuya inversión ya supera en un 22 por 100 el valor de su PIB), casi cuatro veces por debajo del de Francia y tres por debajo de Alemania (que partían de niveles mínimos). También la tasa de retorno se sitúa en la zona baja del conjunto de las dos áreas, aunque el periodo observado resulta excepcional, dadas las circunstancias anómalas de la política monetaria practicada durante la mayor parte del mismo para hacer frente a la Gran Recesión (con EEUU ocupando la posición del cuadro con tasa inferior, al haber aplicado la Fed la política monetaria más activista). Comoquiera que se mire, el Cuadro 8 viene a corroborar los escasos efectos sobre el tamaño y el ritmo de crecimiento del tercer pilar que produce en España la baja intensidad de la política de estímulos observada en el Gráfico 12 y en el Cuadro 7. $\square$ 
que viene haciendo la OCDE (equivalente, grosso modo a las personas con ingresos por debajo del doble del salario mínimo), que se corresponde también con el grupo menos beneficiado por los mecanismos de deducción fiscal del modelo EET. Para este colectivo la reforma debería introducir el subsidio a sus aportaciones (del tipo de subsidio estandarizado de 365 euros al año cuando el beneficiario aporta un 5 por 100 de su salario, disminuyendo proporcionalmente cuando la aportación es menor). Pero con esto no sería suficiente.

La otra medida de estímulo se refiere a la tributación de las retiradas, que es el componente en que el tercer pilar español resulta menos ventajoso, al drenar casi un 40 por 100 del valor actual de todo lo aportado (frente a la mitad de esa cifra en el conjunto del área). Esta es la clave de bóveda para el fortalecimiento del tercer pilar, que exige, además de la subvención a las menores rentas, pasar del sistema EET vigente a un sistema EEt, con tributación minorada de las retiradas. La sugerencia habitual consiste en que tributen como los productos de ahorro (a un tipo medio del 21 por 100 , con escala escasamente progresiva), pero tal cosa resultaría muy gravosa y beneficiaría sobre todo a las mayores rentas, sin aportar un estímulo suficiente para las inferiores y medias, siendo así que estas últimas responden a los incentivos fiscales con "creación de ahorro", mientras que aquellas lo hacen con «desplazamiento del ahorro» 23 .

El esquema estandarizado de la OCDE consiste en minorar la base imponible de las retiradas en un 10 por $100^{24}$. Ese podría ser el

\footnotetext{
23 Véase http://ec.europa.eu/social/BlobServlet?doc/d=4853\&lang/d =es (página 21).

24 En el caso de EEUU se produce una primera minoración sobre la tributación de la pensión de jubilación de la Seguridad Social, que está exenta para ingresos de hasta 25.000 \$/año (32.000 para las parejas), y cuya base imponible se reduce en un 50 por 100 para ingresos individuales de entre 25.000 y 32.000 dólares (o $32.000-44.000$ para las parejas) y en
}

objetivo de las medidas de fomento, aunque solo como media, estableciendo una escala progresiva descendente: empezando por un 40 por 100 para los FP acumulados por jubilados con base reguladora menor o igual al salario mínimo; del 30 por 100 para los jubilados con base reguladora hasta dos SMI, del 20 por 100 hasta tres SMI, del 10 por 100 hasta cuatro y del 5 por 100 para los tramos superiores. Con ello se terminaría de reequilibrar el sesgo en favor de las rentas medias y altas de los modelos EET, se multiplicaría el impacto sobre las aportaciones y se modularía el gasto fiscal de la medida, cuyo objetivo no sería otro que alcanzar en 2050 un tamaño del valor de los fondos equivalente al 145 por 100 del PIB, convenientemente distribuidos a lo largo de la escala de rentas (tomando como punto de referencia el objetivo de que los diferentes tramos de ingresos consigan en 2050 un fondo para pensión equivalente a 3,2 veces su base imponible $)^{25}$.

La estimación realizada en el párrafo anterior no es un cálculo riguroso. Parte de la observación comparada, de la experiencia histórica en España (que hasta 2006 exoneraba fiscalmente el 40 por 100 del capital acumulado, cifra que nos sirve para orientar el máximo de los estímulos para las rentas inferiores) y del perfil de la curva dibujada en el Gráfico 11, convenientemente escalonada, simplificada y traducida a múltiplos de salario mínimo anual. Pero su impacto objetivo a lo largo del tiempo es pura conjetura, sometida a prueba y error. La Comisión del Pacto de Toledo y el Consejo Fiscal deberían asumir la tarea de realizar el seguimiento periódico del impacto de la medida, $\square$

un 15 por 100 para ingresos superiores. Además, los fondos de pensiones reciben una ventaja fiscal media del 24 por 100. Para la comparación con el conjunto del sistema norteamericano, véase Kintzel (2017).

25 Debe observarse, sin embargo, que en 2013-2014 la correlación entre ratios de reposición del sistema legal de pensiones y nivel de cobertura de los sistemas voluntarios en los países OCDE, aunque negativa, era escasa $\left(R^{2}=0,02\right)$ : OECD (2017b, Fig. 5.20). 
del ritmo y la distribución del proceso de acumulación y de su coste fiscal, sugiriendo eventuales correcciones y modulaciones.

No parece conveniente hacer diferenciación alguna entre el tratamiento fiscal de los fondos de pensiones de iniciativa personal y los ocupacionales o de empleo, ya que la portabilidad absoluta que debe caracterizar a estos últimos -OCDE (2016c); UE (2016) - los desvincula de las circunstancias laborales concretas de cada partícipe, tanto a escala nacional como en toda Europa ${ }^{26}$. Eso es lo que ocurre en los principales países que venimos considerando. En los casos de Alemania, Suecia y Austria, que tampoco diferencian el estatus fiscal de unos y otros ${ }^{27}$, existen además fondos en los que el Estado actúa como patrocinador o proporciona una tutela especial. En España se cuenta con la experiencia del fondo AGE, que podría emplearse para promover un fondo abierto a todo tipo de entidades promotoras y partícipes.

Finalmente, aunque existe una corriente analítica que se manifiesta abiertamente a favor de políticas que favorezcan la creación de un mercado amplio, transparente y regulado de rentas vitalicias (annuity products), para minimizar la volatilidad de ingresos a lo largo del periodo de jubilación (Mitchell et al., 2016; Horneff et al., 2016), tampoco cabe pronunciarse por el momento sobre la conveniencia o no de primar especialmente la conversión del fondo de pensiones en este tipo de rentas en el momento de la jubilación, dada la complejidad

26 Véase la iniciativa de la CE a favor de regular e impulsar fondos de pensiones «paneuropeos». Disponible en: https://ec.europa.eu/epsc/ sites/epsc/files/epsc-strategic-note-26-a-pan-european-pensionproduct.pdf

27 Dada la tendencia (OECD, 2016a, cap. 1) hacia el desplazamiento de los planes con beneficios definidos (DB) a planes con aportaciones definidas (DC), la participación de los sindicatos en los planes de empresa ha decaído considerablemente en toda Europa, con excepción de Suecia y Países Bajos (Ebbinghaus, 2017). de ese mercado, la dinámica de innovación que está experimentando y el mayor riesgo que comporta. Sí debería elevarse el nivel regulatorio de exigencia acerca de su transparencia, las garantías de información profesional objetiva y la acción de supervisión (OECD, 2016a, cap. 4; OECD, 2016d).

\section{Conclusión}

En este documento se sintetiza, en primer lugar, la propuesta de reforma del sistema de pensiones formulada en Espina (2017c) y se contrasta con las recomendaciones del FMI, replicando sus escenarios para simular el crecimiento previsible de las bases reguladoras, el poder adquisitivo de las pensiones medias y la ratio que representará el gasto en pensiones en relación con el PIB $\left(g_{p}\right)$. En un escenario con crecimiento de la productividad del 1 por 100 anual y crecimiento similar de los salarios, la pensión media crecería a una tasa anual de 0,35 por 100 en términos reales. En cambio, si la productividad creciera al 1,5 por 100 , el poder adquisitivo de la pensión aumentaría hasta una tasa anual del 0,844 por 100, aunque se opta por el primer escenario debido a los problemas de crecimiento asociados con la Al (inteligencia artificial) ${ }^{28}$. En cualquier caso, la ratio $g_{p}$ aumentaría algo menos de un punto porcentual en cincuenta años, pasando del 12,1 por 100 actual al 13,1 por 100 en 2066.

En segundo lugar, el documento analiza las mejores prácticas en los periodos y los sistemas de cómputo de la base reguladora de $\triangleright$

28 El problema suscitado por Aghion et al. (2017) es asimilable al problema del cambio en el modelo de acumulación durante la primera revolución industrial, de Hicks, Ranis y Fei (Williamson, 2012, p. 34), con la particularidad de que, en lugar del tránsito entre capital variable y capital fijo, nos enfrentaríamos a la transición entre el capital físico y el intangible, que plantea además problemas de medición (Brynjolfsson et al., 2017). 
las pensiones, en los algoritmos para calcular la ratio pensión/salario inicial $(\sigma)$ y en los mecanismos de indexación o revalorización de las mismas. El resultado del estudio indica que, para adoptarlas, España debería computar el conjunto de la carrera laboral (frente a los 25 años que se computarán en 2022), acumulando anualmente 1,556 por 100 de la base reguladora total (frente al 2,703 por 100 acumulado en media actualmente durante solo 37 años). Tras la adopción de esta medida la ratio $\sigma$ inicial acumulada a lo largo de 45 años sería del 70 por 100, similar a la que en la propuesta de Espina (2017c) se alcanzaría en 2063, de modo que aquella medida debería sustituirse por la alternativa de calcular la base reguladora computando toda la carrera (empleando el sistema actual de revalorización) y adoptando un índice de acumulación (accrual rate) de 1,556 por 100 .

La reforma debería ofrecer a todo nuevo pensionista la opción de acogerse llanamente al sistema transitorio o acelerar su aplicación al calcular su pensión inicial con los parámetros de once años más tarde. En este caso se garantizaría que la pensión se revisara anualmente con el IPC, manteniendo constante su poder adquisitivo, y que la edad legal de jubilación se mantuviera en 67 años a partir del momento en que la reforma se le aplique íntegramente, permitiéndole seguir acumulando tasa de reposición a razón de 1 por 100 al año hasta un 75 por 100. Transitoriamente, este ofrecimiento debería hacerse también a los ya jubilados, permitiéndoles recalcular su pensión inicial con parámetros 11 años posteriores a la reforma y acogerse a la garantía de mantenimiento de poder adquisitivo. En cambio, para los jubilados que se acojan llanamente al sistema transitorio, la tasa de acumulación disminuiría anualmente en 0,023 puntos, hasta situarse en 1,556; el periodo computable aumentaría en dos meses al año, hasta situarse en 45 años, y desde 2027 la edad legal de jubilación aumentaría anualmente en un mes por año hasta situarse en 70 años en 2063. En tal caso, la revalorización de la pensión comenzaría aplicando un IRP equivalente al IPC menos 1,75 puntos en 2018 , reduciéndose esta última cifra en 0,0306 puntos al año hasta quedar reducida a cero, momento en que el IRP se igualaría con el IPC.

La última parte del trabajo estudia las mejores prácticas para el tercer pilar de las pensiones (o el segundo pilar privado, en caso de considerase la necesidad de establecerlo como sistema obligatorio, aunque este documento no lo considera imprescindible). Su conveniencia resulta imperiosa en el caso de España, ya que la reforma realizada (y la aquí propuesta, que en esos términos tiene iguales efectos) puede considerarse como la quinta en intensidad de las realizadas en la UE, de acuerdo con el Cuadro 4, por lo que para resultar asumible socialmente a largo plazo su aplicación debería complementarse con un fuerte crecimiento del tercer pilar que compensase con ahorro privado la merma de poder adquisitivo en los ingresos durante la jubilación.

La adopción de las mejores prácticas para el fomento del tercer pilar (una vez descartada su obligatoriedad) consiste, en primer lugar, en subvencionar con 365 euros al año las aportaciones realizadas por el beneficiario cuyos ingresos no superen el doble del salario mínimo, cuando la aportación al fondo de pensiones de su elección equivalga al menos al 5 por 100 de su salario (disminuyendo proporcionalmente cuando la aportación sea menor). En segundo lugar, se mantendría la exención fiscal de las aportaciones a los fondos (y de su rentabilidad) en los términos ya existentes, pero se modificaría la $D$ 
fiscalidad de las retiradas, que seguirían tributando por la tarifa correspondiente del IRPF, aunque deduciendo de la base imponible una parte de las mismas de acuerdo con la siguiente escala: el 40 por 100 para los FP acumulados por jubilados con base reguladora menor 0 igual a un salario mínimo; del 30 por 100 para los jubilados con base reguladora hasta dos SMI; del 20 por 100 hasta tres SMI, del 10 por 100 hasta cuatro y del 5 por 100 para los tramos superiores. Todo ello con el fin de equiparar los incentivos españoles con los del conjunto de la OCDE, persiguiendo el objetivo de que en promedio los nuevos jubilados hayan acumulado en 2050 un FP algo superior al triple de sus ingresos anuales medios, lo que permitiría compensar la merma de riqueza en pensiones derivada de la reforma. En suma, la propuesta consiste en pasar de un sistema fiscal para el ahorro, pensión del tipo EET, a otro del tipo EEt, con carácter progresivo.

\section{Bibliografía}

[1] AGHION, P.; JONES, B.F. y JONES, C.I. (2017). «Artificial Intelligence and Economic Growth». NBER Working Paper 23928. October. Disponible en: http://www.nber.org/ papers/w23928

[2] AMERIKS, J.; BRIGGS, J.S.; CAPLIN, A.; LEE, M.; SHAPIRO, M.D. y TONETTI, C. (2017). «Older Americans Would Work Longer if Jobs Were Flexible». NBER Working Paper 24008. Noviembre. Disponible en: http://www. nber.org/papers/w24008

[3] BRYNJOLFSSON, E.; ROCK, D. y SYVERSON, C. (2017). «Artificial Intelligence and the Modern Productivity Paradox: A Clash of Expectations and Statistics». NBER Working Paper 24001. Disponible en: http://papers. nber.org/papers/w24001?utm_campaign $=n t w \& u t m \_$medium=email\&utm_source $=n t w$

[4] COMISIÓN EUROPEA (2009). «The 2009 Ageing Report: economic and budgetary projections for the EU-27 Member States (2008-2060)». European Economy, n.ㅇ 2. Disponible en: http://ec.europa.eu/economy finance/publications/pages/publication 14992_en.pdf

[5] COMISIÓN EUROPEA (2012). «The 2012 Ageing Report: Economic and budgetary projections for the 27 EU Member States (20102060)». European Economy, n. 2. Disponible en: http://ec.europa.eu/economy_finance/publications/european_economy/2012/pdf/ ee-2012-2_en.pdf

[6] COMISIÓN EUROPEA (2015a). «The 2015 Ageing Report: Economic and budgetary projections for the 28 EU Member States (20132060)». European Economy, n.ํ 3. Disponible en: http://ec.europa.eu/economy_finance/publications/european_economy/2015/pdf/ ee3_en.pdf

[7] COMISIÓN EUROPEA (2015b). «The 2015 Ageing Report: Underlying Assumptions and Projection Methodologies». European Economy. Disponible en: http://ec.europa.eu/economy_finance/publications/european_economy/2014/pdf/ee8_en.pdf

[8] DÍAZ-GIMÉNEZ, J. y DÍAZ-SAAVEDRA, J. (2017). «The future of Spanish pensions», Journal of Pension Economics \& Finance, vol. 16, n. .2 , pp. 233-265 (abril). Version previa diponible en: http://javierdiazgimenez.com/ res/PEN3-PAP.pdf

[9] EBBINGHAUS, B. (2015). «The Privatization and Marketization of Pensions in Europe: A Double Transformation Facing the Crisis". European Policy Analysis, vol. 1, n. 1. Primavera.

[10] EBBINGHAUS, B. (2017). «The Role of Trade Unions in Pension Policymaking and Private Pension Governance in Europe», en D. Natali (ed.): The New Pension Mix in Europe: Recent Reforms, Their Distributional Effects and Political Dynamics. Brussels: PIE Peter Lang, 206-38.

[11] ESPINA, A. (2017b). «El sistema español de pensiones en el siglo XXI: Evidencia disponible y análisis gráfico». Boletín económico de ICE, Información Comercial Española, n.ำ 3091, pp. 47-81, (septiembre). Disponible en: http:// www.revistasice.com/es-ES/BICE/Paginas/ Sumario.aspx $?$ numero $=3091$ 
[12] ESPINA, A. (2017c). «Equidad y sostenibilidad: una propuesta para completar la reforma del sistema español de pensiones contributivas». CD 111, 21 de julio de 2017, 33 páginas. Dirección General de Política Económica. MEIC. Disponible en: http://imagenesbibliotecacentral.minhap.gob.es/pdfpublicaciones// Literaturagris/cd111_2017.pdf

[13] GARCÍA-VAQUERO, V. (2010). «Los instrumentos de ahorro-previsión en España: desarrollos recientes». Banco de España. Boletín Económico, marzo de 2010. Disponible en: https://www.bde.es/f/webbde/SES/Secciones/Publicaciones/InformesBoletines Revistas/BoletinEconomico/10/Mar/Fich/art4. pdf

[14] GROSSMAN, G. M.; HELPMAN, E.; OBERFIELD, E. y SAMPSON, T. (2017). «The Productivity Slowdown and The Declining Labor Share: A Neoclassical Exploration». NBER Working Paper 23853. Disponible en: http://www.nber.org/papers/w23853

[15] HERNÁNDEZ DE COS, P.; JIMENO, J.F. y RAMOS, R. (2017). El sistema público de pensiones en España: situación actual, retos $y$ alternativas de reforma. BdE. Documento Ocasional n.. 1701 . Disponible en: $h t t p: / / w w w$. bde.es/f/webbde/SES/Secciones/ Publicaciones/PublicacionesSeriadas/ DocumentosOcasionales/17/Fich/do1701.pdf

[16] HORNEFF, V.; MAURER, R. y MITCHELL, O.S. (2016). «Putting the Pension Back in 401(K) Plans: Optimal Versus Default Longevity Income Annuities». NBER Working Paper 22717. Octubre. Disponible en: http:// www.nber.org/papers/w22717

[17] JIMENO, J. F. (2003). «La equidad intrageneracional de los sistemas de pensiones". Revista de Economía Aplicada, n. ${ }^{\circ} 33$, vol. 11 , pp. 5-48. Disponible en: $h t t p: / / w w w . r e v e c a p$. com/revista/numeros/33/pdf/jimeno.pdf

[18] KINTZEL, D. (2017). "Social Security Retirement Benefits and Private Annuities: A Comparative Analysis». Issue Paper n. ${ }^{\circ}$ 201701. Mayo. Disponible en: https://www.ssa.gov/ policy/docs/issuepapers/ip2017-01.pdf

[19] MENEU, R.; DEVESA, E.; DEVESA,; M.; DOMÍNGUEZ, I. y ENCINAS, B. (2017).
«Adjustment mechanisms and intergenerational actuarial neutrality in pension reforms". International Social Security Review, vol. 69, n.. 1, pp. 87-107. January-March 2016.

[20] MITCHELL, O.S.; MAURER, R. y ORSZAG, J.M. (eds.) (2016). Retirement System Risk Management: Implications of the New Regulatory Order. O. U. Press.

[21] OECD (2015). Pensions at a glance. OECD and G20 indicators.

[22] OECD (2016a). Pensions Outlook 2016.

[23] OECD (2016b). Generation next: how to prevent ageing unequally progress report, DELSA/ELSA (2016)16, Octobre, 17.

[24] OECD (2016c). Core Principles of Private Pension Regulation. Disponible en: http:// www.oecd.org/finance/principles-privatepension-regulation.htm

[25] OECD (2016d). Life Annuity Products and Their Guarantees. Paris.

[26] OECD (2017a). Pension Markets in Focus, 2017 edition. Disponible en: $h t t p: / / w w w . o e c d$. org/pensions/private-pensions/PensionMarkets-in-Focus-2017.pdf

[27] OECD (2017b). Preventing Ageing Unequally.

[28] PELLEGRINO, B. y ZINGALES, L. (2017). "Diagnosing the Italian Disease». NBER Working Paper 23964. October. Disponible en: http://www.nber.org/papers/w23964

[29] STIGLITZ, J.E. (2017a). «Where Modern Macroeconomics Went Wrong". NBER Working Paper 23795. September. Disponible en: http://www.nber.org/papers/w23795

[30] STIGLITZ, J.E. (2017b). «Pareto Efficient Taxation and Expenditures: Pre- and ReDistribution». NBER Working Paper 23892. September. Disponible en: http://www.nber. org/papers/w23892

[31] UE (2016/2341). «Directiva relativa a las actividades y la supervisión de los fondos de pensiones de empleo (FPE)». Diario Oficial de la Unión Europea (14 de diciembre). Disponible en: http://eur-lex.europa.eu/legal-content/ES/ TXT/PDF/?uri=CELEX:32016L2341\&from $=E N$

[32] WILLIAMSON, J. G. (2012). El desarrollo económico mundial en perspectiva histórica. Prensas de la Universidad de Zaragoza. 
BOLETÍN ECONÓMICO DE INFORMACIÓN COMERCIAL ESPAÑOLA (BICE) ISSN 0214-8307

\section{SUSCRIPCIÓN ANUAL}

\begin{tabular}{|c|c|c|c|}
\hline \multicolumn{2}{|c|}{ BOLETÍN ECONÓMICO DE INFORMACIÓN COMERCIAL ESPAÑOLA (12 NÚMEROS) } \\
\hline & $\begin{array}{c}\text { ESPAÑA } \\
\mathbf{1} \text { año }\end{array}$ & $\begin{array}{c}\text { UNIÓN EUROPEA } \\
\mathbf{1} \text { año }\end{array}$ & $\begin{array}{c}\text { RESTO DEL } \\
\text { MUNDO } \\
1 \text { año }\end{array}$ \\
\hline SUSCRIPCIÓN & $65,00 €$ & $85,00 €$ & $85,00 €$ \\
\hline $\begin{array}{c}\text { Gastos de envío } \\
\text { España }\end{array}$ & $5,76 €$ & $24,36 €$ & $30,00 €$ \\
\hline $\begin{array}{c}\text { Más 4\% de IVA. } \\
\text { Excepto Canarias, Ceuta y Melilla }\end{array}$ & $2,83 €$ & & $115,00 €$ \\
\hline TOTAL & $\mathbf{7 3 , 5 9 €}$ & $\mathbf{1 0 9 , 3 6} €$ & \\
\hline & & & \\
\hline
\end{tabular}

\section{EJEMPLARES SUELTOS}

\begin{tabular}{|c|c|c|c|}
\hline BOLETÍN ECONÓMICO & DE INFORMACIÓN & COMERCIAL ESPAÑOL & \\
\hline & $\begin{array}{l}\text { ESPAÑA } \\
1 \text { ejemplar }\end{array}$ & $\begin{array}{l}\text { UNIÓN EUROPEA } \\
1 \text { ejemplar }\end{array}$ & $\begin{array}{l}\text { RESTO DEL } \\
\text { MUNDO } \\
1 \text { ejemplar }\end{array}$ \\
\hline NÚMERO SUELTO & $7,00 €$ & $9,00 €$ & $9,00 €$ \\
\hline $\begin{array}{l}\text { Gastos de envío } \\
\text { España }\end{array}$ & $0,48 €$ & $2,03 €$ & $2,50 €$ \\
\hline $\begin{array}{l}\text { Más } 4 \% \text { de IVA. } \\
\text { Excepto Canarias, Ceuta y Melilla }\end{array}$ & $0,30 €$ & & \\
\hline TOTAL & $7,78 €$ & $11,03 €$ & $11,50 €$ \\
\hline \multirow[t]{2}{*}{ BOLETÍN ECONÓMICO } & DE INFORMACIÓN & COMERCIAL ESPAÑOL & \\
\hline & $\begin{array}{l}\text { ESPAÑA } \\
1 \text { ejemplar }\end{array}$ & $\begin{array}{l}\text { UNIÓN EUROPEA } \\
1 \text { ejemplar }\end{array}$ & $\begin{array}{c}\text { RESTO DEL } \\
\text { MUNDO } \\
1 \text { ejemplar }\end{array}$ \\
\hline $\begin{array}{l}\text { NÚMERO SUELTO } \\
\text { EXTRAORDINARIO }\end{array}$ & $12,00 €$ & $15,00 €$ & $15,00 €$ \\
\hline Gastos de envío España & $0,48 €$ & $2,03 €$ & $2,50 €$ \\
\hline $\begin{array}{c}\text { Más 4\% de IVA. } \\
\text { Excepto Canarias, Ceuta y Melilla }\end{array}$ & $0,50 €$ & & \\
\hline TOTAL & $12,98 €$ & $17,03 €$ & $17,50 €$ \\
\hline
\end{tabular}

\section{DATOS}

Nombre y apellidos

Empresa

Domicilio

D.P.

N.I.F.

Teléf.

Email
DATOS DEL EDITOR:

NIF:S2800568D

Transferencia a la cuenta de ingresos por venta de publicaciones del Ministerio de Economía y Competitividad.

IBERCAJA. Calle Alcalá 29. 28014 MADRID (ESPAÑA) CÓDIGO CUENTA CLIENTE: 2085-9252-07-0330598330 CÓDIGO BIC DE IBERCAJA: CAZRES2Z

IBAN: ES47 2085-9252-07-0330598330

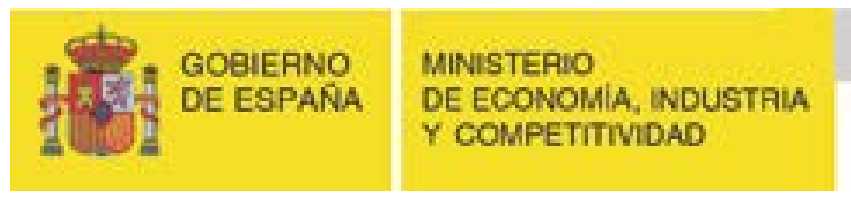

\section{SUESECAETARIA}

SECRETARIA GENERAL TECNICA

DUECIRECCION GENTRM OS

ESTuONOS, BNFOSACXCN Y PUSUCACONES

Suscripciones y ventas por correspondencia:

Paseo de la Castellana, 162, 9ª Planta, 28046 Madrid. Teléfono 916037993 / 97

Suscripciones a través de la página web del Ministerio de Economía, Industria y Competitividad distribucionpublicaciones@mineco.es 


\section{NORMAS DE ESTILO DE PUBLICACIÓN}

La persona o personas interesadas en presentar un artículo para su publicación en el Boletín de Información Comercial Española (BICE) deberán enviar el artículo en formato Microsoft Word a la dirección de correo electrónico revistasice.sscc@comercio.mineco.es

El documento debe cumplir las siguientes características:

1. Ser material original no publicado ni presentado en otro medio de difusión.

2. La extensión total del trabajo (incluyendo cuadros, gráficos, tablas, notas, etcétera) no debe ser inferior a 15 páginas ni superior a 20. La fuente será Times New Roman, tamaño 12 y espaciado doble. Estar paginado en la parte inferior derecha de cada página.

3. En la primera página se hará constar el título del artículo que deberá ser breve, claro, preciso e informativo y la fecha de conclusión del mismo. Nombre y dos apellidos del autor o autores, filiación institucional, dirección, teléfono y correo electrónico de cada uno de ellos, así como la forma en que desean que sus datos aparezcan.

4. En la segunda página del texto se incluirá:

- El título.

- Un resumen del trabajo con una extensión máxima de 10 líneas con la siguiente estructura: objetivo, método y principal resultado o conclusión.

- De 2 a 6 palabras clave que no sean coincidentes con el título.

- De 1 a 5 códigos de materias del Journal of Economic Literature (clasificación JEL) para lo cual pueden acceder a la siguiente dirección electrónica:

https://www.aeaweb.org/jel/guide/jel.php

5. En las siguientes páginas se incluirán el texto, la información gráfica y la bibliografía con la siguiente organización.

- Se incluirá, por este orden, introducción, desarrollo, conclusiones y bibliografía y anexos si los hubiera. Los apartados y subapartados se numerarán en arábigos respondiendo a una sucesión continuada utilizando un punto para separar los niveles de división, según el siguiente modelo:

\section{Título del apartado}

\subsection{Título del apartado}

\subsubsection{Título del apartado}

\section{Título del apartado}

- Las notas de pie de página irán integradas en el texto y su contenido debe estar al final de su misma página en tamaño 10 y espacio sencillo.

- En un archivo Excel independiente se incluirá la representación gráfica (cuadros, gráficos, diagramas, figuras, etc.), que debe llevar título, estar numerada y referenciada en el texto.

En la parte inferior se incluirá la fuente de información y/o notas aclaratorias.

- Las citas de libros y artículos en el texto, se indicarán entre paréntesis con el apellido del autor y el año. Ej.: (Martínez, 1991).

- Las referencias a siglas deben ir acompañadas, en la primera ocasión en que se citen, de su significado completo.

- La bibliografía se ordenará alfabéticamente siguiendo las normas de la American Psychological Association (Harvard-APA): http://cibem.org/paginas/img/apa6.pdf

Libros

APELLIDOS, A.A. (año de publicación). Título del libro (edición) (volumen). Ciudad: Editorial.

Artículo en revista científica

APELLIDOS, A.A. (año de publicación). «Título del artículo». Título de la revista, volumen (número), números de páginas.

\section{Documento en línea}

APELLIDOS, A.A. u ORGANISMO (año, mes de publicación). Título, [en línea]. Ciudad: Editorial. Disponible en:

http://cenamb.rect.ucv.ve/siamaz/dicciona/canaima/canaima2.htm [Recuperado: 2000, 3 de junio]. 